\title{
The causal role of magnesium deficiency in the neuroinflammation, pain hypersensitivity and memory/emotional deficits in ovariectomized and aging mice
}

Xian-guo Liu ( $\nabla$ liuxg@mail.sysu.edu.cn )

Sun Yat-sen University Zhongshan School of Medicine https://orcid.org/0000-0002-4352-8687

Jun Zhang

Sun Yat-sen University Zhongshan School of Medicine

Chun-lin Mai

Sun Yat-sen University Zhongshan School of Medicine

Ying Xiong

Sun Yat-sen University Zhongshan School of Medicine

Zhen-Jia Lin

Sun Yat-sen University Zhongshan School of Medicine

Ying-Tao Jie

Sun Yat-sen University Zhongshan School of Medicine

Jie-Zhen Mai

Sun Yat-sen University Zhongshan School of Medicine

Chong Liu

Guangdong Provincial People's Hospital

Man-Xiu Xie

Sun Yat-sen University Cancer Center

Xin Zhou

Guangdong Provincial People's Hospital

\section{Research}

Keywords: Magnesium-L-threonate, Ovariectomy, Aging, Tumor necrosis factor-alpha, Nuclear factorkappaB, Cognitive deficit, spinal dorsal horn, Hippocampus

Posted Date: April 3rd, 2021

DOI: https://doi.org/10.21203/rs.3.rs-379976/v1 
License: (c) (i) This work is licensed under a Creative Commons Attribution 4.0 International License. Read Full License 


\section{Abstract}

Background: Postmenopausal women often suffer from chronic pain, memory decline and mood depression. The mechanisms underlying the neuronal disorders are not fully understood and effective treatment is still lacking.

Methods: Oral administration of magnesium-L-threonate was tested to treat the neuronal disorders in ovariectomized and aging mice. The pain hypersensitivity, memory function and depression were measured with a set of behavioral tests. Western blots and immunochemistry were used to assess molecular changes.

Results: Chronic oral administration of magnesium-L-threonate substantially prevented or reversed the chronic pain, and memory/emotional deficits in both ovariectomized and aging female mice. We found that phospho-p65, an active form of nuclear factor-kappaB, tumor necrosis factor-alpha and interleukin1 beta were significantly upregulated in the neurons of dorsal root ganglion, spinal dorsal horn and hippocampus in ovariectomized and aging mice. The microglia and astrocytes were activated in spinal dorsal horn and hippocampus. The peptidergic $\mathrm{C}$-fibers in dorsal horn were increased, which are associated with potentiation of $\mathrm{C}$-fiber-mediated synaptic transmission in the model mice. In parallel with neuroinflammation and synaptic potentiation, free $\mathrm{Mg}^{2+}$ levels in plasma, cerebrospinal fluid and dorsal root ganglion neurons were significantly reduced. Oral magnesium-L-threonate normalized the neuroinflammation, synaptic potentiation and $\mathrm{Mg}^{2+}$ deficiency, but did not affect the estrogen decline in ovariectomized and aging mice. Furthermore, in cultured dorsal root ganglion neurons estrogen elevated intracellular $\mathrm{Mg}^{2+}$, and depressed the upregulation of phospho-p65, tumor necrosis factor-alpha and interleukin- 1 beta exclusively in the presence of extracellular $\mathrm{Mg}^{2+}$.

Conclusions: Estrogen decline in menopause causes neuroinflammation by reducing intracellular $\mathrm{Mg}^{2+}$ in neurons, leading to chronic pain, memory/emotional deficits. Thus, supplement $\mathrm{Mg}^{2+}$ by oral magnesiumL-threonate may be a novel approach for treating menopause-related neuronal disorders.

\section{Introduction}

Many postmenopausal women suffer from chronic pain [1-3], memory decline [4] and mood depression [5]. The mechanisms underlying the comorbidity of the somatosensory and cognitive/emotional deficits are largely unknown.

Our previous works showed that neuroinflammation, characterized by the upregulation of proinflammatory cytokines, such as tumor necrosis factor-alpha (TNF- $\alpha$ ) and interleukin-1beta (IL-1 $\beta$ ), and glial activation, contributes to chronic neuropathic pain and memory/emotional impairments following peripheral nerve injury[6-10]. Similarly, it has been proposed that inflammation resulting from estrogen decline may cause cognitive disorders in menopause women [11]. The data suggested that 
neuroinflammation might be also a common cause for chronic pain and cognitive/emotional deficits in menopause conditions. However, how the estrogen decline leads to neuroinflammation remains elusive.

It has been shown that serum $\mathrm{Mg}^{2+}$ is decreased in postmenopausal women $[12,13]$ and in ovariectomized rats [14]. Interestingly, experimental $\mathrm{Mg}^{2+}$ deficiency in the rat induces an inflammatory syndrome characterized by leukocyte and macrophage activation, and release of inflammatory cytokines [15]. $\mathrm{Mg}^{2+}$ deficiency also results in anxiety and depression in animals and humans [16]. Likewise, our recent works shown that $\mathrm{Mg}^{2+}$ deficiency causes chronic pain [17] and memory/emotional deficits [18, 19] by activation of tumor necrosis factor-alpha (TNF-a)/ nuclear factor-kappaB (NF-kB) pathway in the rats treated with antineoplastic agents, including vincristine and cyclophosphamide. Previous works including ours show that chronic oral administration of magnesium-L-threonate (L-TAMS, also called $\mathrm{MgT}$ ), which can elevate brain $\mathrm{Mg}^{2+}$, improves spatial learning in both naïve rats [20] and in a mouse model of Alzheimer's disease [21]. Oral L-TAMS also prevents and restores the memory deficits induced by peripheral nerve injury [22], and the chronic pain [17] and memory/emotional deficits $[18,19]$ induced by the antineoplastic agents. A clinical trial indicates that the global cognitive ability of older adults can be improved by oral L-TAMS [23]. Together, these clinical and experimental data suggested that $\mathrm{Mg}^{2+}$ deficiency might play a key role in the neuroinflammation that induces neuronal disorders. As $31 \%$ of $\mathrm{Mg}^{2+}$ in the body is distributed inside cells, where it functions as a co-activator for 600 enzymes [24], intracellular $\mathrm{Mg}^{2+}$ deficiency may trigger neuroinflammation. However, the causal link between intracellular $\mathrm{Mg}^{2+}$ level and neuroinflammation in estrogen decline is still not determined.

In the present work, with use of ovariectomized and aging mice and cell culture, we asked following questions: Could estrogen decline cause intracellular $\mathrm{Mg}^{2+}$ deficiency? Could intracellular $\mathrm{Mg}^{2+}$ deficiency directly induce neuroinflammation? Is chronic oral administration of L-TAMS capable of preventing and reversing the estrogen decline-induced neuroinflammation, chronic pain and memory/emotional deficits?

\section{Materials And Methods}

\section{Animals}

Adult female (8-12 weeks-old) C57BL/6 mice and aging (12-mouth-old) female C57BL/ 6 mice were purchased from the Institute for Experimental Animals of Sun Yat-sen University (Guangzhou, China). The mice were housed in a $12 \mathrm{~h}$ light/dark cycle $(06: 00-18: 00 \mathrm{~h})$ and temperature $\left(24 \pm 1^{\circ} \mathrm{C}\right)$ controlled cage with $50-60 \%$ humidity. The mice had access to sterile water and standard laboratory chow ad libitum. All experimental protocols and animal handling procedures were approved by the Animal Care Committee of Sun Yat-sen University and in accordance with the guidelines of the National Institutes of Health on animal care and ethical guidelines. Animals were randomly assigned to each group.

\section{Treatment with magnesium-L-threonate (L-TAMS)}


According to previous studies [20, 25], mice received L-TAMS (Neurocentria Inc., Walnut Creek, CA, USA) at a dose of $910 \mathrm{mg} / \mathrm{kg} / \mathrm{d}(75 \mathrm{mg} / \mathrm{kg} / \mathrm{d}$ elemental magnesium) daily in the drinking water $(6 \mathrm{ml} / \mathrm{d} / \mathrm{mouse})$. Oral application of L-TAMS was initiated 1 week after ovariectomy (OVX) in adult female mice and continued until the end of experiments. Aging mice received L-TAMS throughout the experiments.

\section{Ovariectomy (OVX)}

Ovariectomy is a model of menopause [26]. OVX was performed by double dorsolateral incisions according to previous work [27]. The mice were anesthetized with $2 \%$ isoflurane (RWD Life Science, China). Dorsal incisions were made in the area between the last rib and hips, each ovary together with its capsule and part of the oviduct was removed. In sham operated mice, the ovaries were identically exposed but not removed.

\section{Behavioral tests}

All behavioral tests were conducted at 9:00 a.m. $-5: 00$ p.m. The experimenter who conducted the behavioral tests was blinded to all treatments.

Mechanical withdrawal threshold. The mice were acclimated to the test environment for 3 days before the formal experiments. Before each test, the mice were allowed to acclimate again for 30 minutes. $50 \%$ paw withdrawal threshold (PWT) was assessed with the up-down method described previously [28]. The procedure was the same as previous studies [6]. Briefly, mice were placed on a wire grid and the plantar surface of the hind paw was stimulated with a set of Von Frey filaments $(0.04-2 \mathrm{~g}$ for mice; North Coast medical). Quick withdrawal or licking of the paw in response to the mechanical stimulus was considered a positive response. Basal nociceptive sensitivity was tested before OVX and L-TAMS administration. The mice with basal PWT $\leq 0.16 \mathrm{~g}$ were excluded. Mechanical withdrawal threshold was measured weekly in each group.

Conditioned place preference (CPP). CPP was used to determine the presence of spontaneous (ongoing) pain in animals. Relief of pain is a form of rewarding, and clonidine as an analgesic agent was not rewarding in the absence of pain but became rewarding when there is ongoing pain [29]. To put it simply, mice were given intraperitoneal injections of $0.1 \mathrm{mg} / \mathrm{kg}$ clonidine or equivalent saline in paired boxes with different patterns and colors. After training three times in each box, the two boxes were connected and the mice were allowed free access for 15 min to either box. An infrared camera was used to record the trace of mice. The ratio of time that each mouse spent in clonidine paired box and saline paired box were recorded for statistical analysis. CPP was performed 11 weeks after oral administration of L-TAMS or vehicle.

Novel object recognition test (NORT). NORT was applied to assess short-term memory function as previously described $[9,30]$. Briefly, mice were tested on a round field with a diameter of $50 \mathrm{~cm}$. In the first stage, each mouse was placed in the arena for 5 minutes, and two identical "old objects" were placed. Ten minutes later, a new different object replaced the less preferred old one, and each mouse was allowed to 
explore the two objects for 5 minutes. The recognition index was calculated as the ratio of time that the mice spent exploring the novel object over total exploration time. NORT was administered at a time point of 11 weeks after oral administration of L-TAMS.

$Y$-maze. Spontaneous alternation that measures spatial working memory was assessed with a Y-maze apparatus, which is consisting of $a, b$ and $c$ three Plexiglas wall-protected arms $(60 \mathrm{~cm}$ long $\times 10 \mathrm{~cm}$ wide $\times 20 \mathrm{~cm}$ high at $\left.120^{\circ}\right)$. Briefly, mice were allowed to explore all three arms of the maze freely, this behavior was driven by the innate curiosity of rodents to explore new areas [31]. 8-minute trials per animal were recorded by Ethovision 3.1 software (Noldus, Netherlands). Percentage of alternations (i.e., abc, bca, and cba) normalized to total triplet arm entries were used as an index of spatial working memory. Y-maze test was performed 11 weeks after oral administration of L-TAMS.

Forced swimming test (FST). The FST was applied to assess the depression state of animals [32, 33]. Mice were forced to swim in a cylindrical barrel $(25 \mathrm{~cm}$ in diameter and $45 \mathrm{~cm}$ high) containing $30 \mathrm{~cm}$ of water at $25 \pm 1^{\circ} \mathrm{C}$ for $6 \mathrm{~min}$. The immobility time in the last $4 \mathrm{~min}$ was recorded as an indicator of depression-like behavior.

Tail suspension test (TST). The TST shares a common behavioral measurement with the FST [34]. The tails of mice were suspended using adhesive tape for $6 \mathrm{~min}$, and the time of immobility in the last 4 min is recorded. FST and TST were performed at 11 weeks of oral administration of L-TAMS, and after other behavioral tests have been completed.

\section{Electrophysiologic Recording.}

The electrophysiology recording was performed 12 weeks after L-TAMS treatment. Protocols of recording the $\mathrm{C}$-fiber evoked field potential in the spinal dorsal horn have been described in our previous studies [6, 35]. Briefly, mice were anesthetized with urethane (Sigma, USA, $1.5 \mathrm{~g} / \mathrm{kg}$, i.p.). Laminectomy was performed and the left sciatic nerve trunk was explored. The sciatic nerve was stimulated by test stimuli ( 0.5 ms duration, at increasing voltages $1-25 \mathrm{~V}$ ) with a bipolar platinum hook electrode. C-fiber evoked field potentials were recorded in the superficial spinal dorsal horn ( $L 4$ and L5 segments) with a glass microelectrode (filled with $0.5 \mathrm{M}$ sodium acetate, impedance 1-3M $\Omega$ ). The amplitudes of C-fiber evoked field potentials were recorded and analyzed with WinLTP program (http://www.winltp.com/). The animals were euthanized at the end of the experiments.

\section{Culture of DRG Neurons}

Dorsal root ganglion (DRG) neurons were dissociated and cultured following our previous work [36]. Briefly, mice were euthanized by $\mathrm{CO}_{2}$ and then decapitated immediately. DRG were excised with sharp tweezers and freed from their capsule and connective tissue, this process was performed on ice. DRGs were cut up with sharp scissors and digested with $2 \mathrm{mg}$ trypsin (Sigma, USA) and $3 \mathrm{mg}$ collagenase (Sigma, USA) in $5 \mathrm{ml} \mathrm{DMEM/F12} \mathrm{medium} \mathrm{(GIBCO,} \mathrm{USA)} \mathrm{for} \mathrm{about} 25$ minutes in $37^{\circ} \mathrm{C}$ water bath. To stop the digestion, $5 \mathrm{ml}$ of complete medium (10\% fetal bovine serum, 1\% Penicillin-Streptomycin Solution, $1 \%$ 
glutamine in DMEM/F12 medium, all from Gibco, Grand Island, NY) was added. After mechanical and enzymatic dissociation, DRG neurons were collected and seeded on a 24-well plate coated with poly-Llysine (Sigma, USA) and then transferred to the humidified atmosphere $\left(5 \% \mathrm{CO} 2,37^{\circ} \mathrm{C}\right)$ for 4 hours. And then the complete medium was changed to remove the non-adherent cells. In addition, custom magnesium-free medium was used to test $\mathrm{Mg}^{2+}$ deficits in neuroinflammation (Fig. $10 \mathrm{C}$ ). In this experiment, $17 \beta$ - estradiol was added to the medium on the second day and third day. The cultured DRG neurons were fixed by $4 \%$ paraformaldehyde for immunofluorescence on the fourth day.

\section{Western Blot}

After 12 weeks of oral administration of L-TAMS or vehicle, cardiac perfusion with $4^{\circ} \mathrm{C}$ PBS buffer was performed under anesthesia with urethane (Sigma, USA, $1.5 \mathrm{~g} / \mathrm{kg}$, i.p.) of mice. And then the hippocampus and spinal dorsal horn in each group were harvested and homogenized with protease inhibitor cocktail (Roche, USA) and phosphatase inhibitor (Roche, USA). Proteins in samples were separated on $12.5 \%$ PAEG gel (EpiZyme, China), and then transferred to PVDF membranes (Millipore, USA). Membranes were blocked in $5 \%$ bovine serum albumin (BSA) solution for $60 \mathrm{~min}$ at room temperature and then incubated with primary antibodies: TNF-a (1:1000, rabbit; Bioworld Technology, Inc., Louis Park, MN, USA), phosphorylated NF-KB p65 (Ser311) (1:1000; Affinity Biosciences, OH, USA), IL-1ß(1:1000, rabbit, Abcam, Cambridge, UK), CGRP (1:5000, mouse, Abcam, Cambridge, UK), $\beta$-actin (1:1000, mouse; Cell Signaling Technology, MA, USA) overnight at $4^{\circ} \mathrm{C}$. Horseradish peroxidase-conjugated IgG was applied for $1 \mathrm{~h}$. Chemiluminescent liquid (Millipore, USA) was used to detect the immune complex. Bands were quantified using a computer-assisted imaging analysis system (ImageJ; National Institutes of Health, Bethesda, MD, USA).

\section{Immunofluorescence}

Mice treated with L-TAMS or vehicle for 12 weeks were anesthetized with urethane (Sigma, $1.5 \mathrm{~g} / \mathrm{kg}$, i.p.), and then perfused intracardially with $4^{\circ} \mathrm{C}$ PBS followed by $4 \%$ paraformaldehyde (PFA). L4-5 DRG, L3-L5 segments of spinal cord and hippocampus were harvested and post-fixed in the 4\% PFA solution for 4-6 hours, then transferred to $30 \%$ sucrose in PBS for 3 days at $4^{\circ} \mathrm{C}$. The tissues were sliced into $20 \mu \mathrm{m}$ sections using a cryotome (CM3050S, Leica, Wetzlar, Germany) and processed for immunohistochemical staining. The cultured DRG neurons were fixed with $4 \%$ PFA for 20 mins and then washed in PBS. The tissue sections and cultured DRG neurons were blocked for 60 and $30 \mathrm{~min}$ at room temperature, and then incubated overnight at $4^{\circ} \mathrm{C}$ with TNF-a (1:200, Rabbit, Bioworld Technology, Inc., MN, USA), IL-1 $\beta$ (1:200, goat, R\&D Systems, USA), phosphorylated NF-kB p65 (Ser311) (1:100; Affinity Biosciences, OH, USA), CGRP (1:500, goat, Abcam, Cambridge, UK), plant lectin B4 (IB4; 1:200; Sigma, USA), NeuN (1:400, mouse; Millipore, USA), GFAP (1:800, mouse, Cell Signaling Technology, MA, USA), and Iba1 (1:500, goat, Abcam, Cambridge, UK)overnight at $4{ }^{\circ} \mathrm{C}$. Then the samples were incubated with secondary antibodies (Alexa Fluor ${ }^{\circledR} 488,555,647$; Life Technologies, CA, USA) for $1 \mathrm{~h}$ at room temperature and mounted on coverslips with Fluoromount-G with DAPI (Southern Biotech, Birmingham, AL, USA). Fluorescent images were obtained with EVOS FL microscope (Thermo Fisher Scientific, USA), and Nikon C2 confocal 
microscopes. All parameters such as exposure time and gain were fixed to ensure standardization between each sample. ImageJ software (National Institutes of Health, USA) was used to analyze the count of cells and fluorescence intensity. Fluorescent signal intensity was quantified using relative integrated density (IntDen), an appropriately threshold was set and kept constant in all groups. IntDen of sham or control group was set as baseline, the data from other groups were normalized with the baseline.

\section{Measurement of Extracellular and Intracellular Free Magnesium}

The plasma and cerebrospinal fluid (CSF) of mice treated with L-TAMS or vehicle for 12 weeks were collected from the left ventricle and foramen magnum respectively. The concentrations of free $\mathrm{Mg}^{2+}$ in the plasma and CSF were measured with calmagite chromometry method [37].

The preparation method of DRG neuron suspension is the same as the above method of DRG neuron culture. The intracellular free $\mathrm{Mg}^{2+}$ in DRG neurons was determined by flow cytometry (FCM) [17]. In brief, DRG neurons were incubated with Magnesium Green (Invitrogen, Massachusetts, USA) in PBS for 30 min at $37^{\circ} \mathrm{C}$. Then the DRG neurons were washed in PBS and fixed by $1 \%$ PFA. The data were collected by flow cytometry (CytoFLEX S, Beckman Coulter, USA). The mean fluorescence intensity of 30,000 neurons in each mouse was used to measure the intracellular free $\mathrm{Mg}^{2+}$ in the neurons. In cultured DRG neurons, the intracellular free $\mathrm{Mg}^{2+}$ was determined by a multifunctional microplate reader (Synergy HTX) using Magnesium Green (Invitrogen, Massachusetts, USA). The protocol of antibody incubation and fixation are the same as above.

\section{Plasma $17 \beta$-Estradiol measurement}

Mice treated with L-TAMS for 12 weeks were anesthetized with urethane, the blood was harvested from hearts, and the plasma was stored at $-80^{\circ} \mathrm{C}$ until use. Estrogen in mouse plasma was measured using commercially available Estradiol ELASA kits (Cayman, Item No. 501890) according to the manufacturer's instructions. This kit is a competitive assay that has a range of $0.61-10,000 \mathrm{ng} / \mathrm{L}$. Extraction of the sample with methanol before measurement was made to increase the accuracy of the test. $50 \mu$ l of each plasma sample was used according to the manufacturer's specification.

\section{Statistical analysis}

All data are presented as the mean \pm SEM. GraphPad Prism 7.0 software (GraphPad Software, CA, USA) was used to calculate statistical significance. The results of mechanical pain behavior and electrophysiological data were analyzed with two-way ANOVA followed by Tukey's post hoc test. Other results were analyzed with one-way ANOVA followed by Tukey's post hoc test. $P<0.05$ was considered as significant difference.

\section{Results}




\section{Chronic oral magnesium-L-threonate attenuates the pain hypersensitivity and potentiation at C-fiber synapses in both ovariectomized and aging female mice}

We first tested if supplement $\mathrm{Mg}^{2+}$ by oral administration of L-TAMS is able to prevent the chronic pain and the memory/emotional deficits induced by ovariectomy (OVX). As shown in Fig.1A, compared to sham mice (open circle), the paw withdrawal thresholds (PWT) elicited by mechanical stimuli decreased in OVX mice treated with either normal water and L-TAMS with time, while the change was significantly smaller in L-TAMS-treated mice (Fig. 1A, triangle) than that in water-treated mice (Fig. 1A, square). LTAMS did not affect PWT in sham mice (Fig. 1A, filled circle). The results indicate that oral L-TAMS prevents the mechanical allodynia induced by OVX but has no effect on pain sensitivity in sham mice. We also tested if oral L-TAMS might also attenuate the spontaneous pain induced by OVX with CPP test, and found that OVX mice treated with L-TAMS spend less time in the chamber receiving clonidine than those treated with vehicle (Fig. 1B). While no difference was detected between the two treatments in sham mice. The results are in consistence with the clinical observation that estrogen decline leads to chronic pain in menopause women $[1,2]$. To further investigate the effect of L-TAMS on the chronic pain sensitivity induced by estrogen decline, we measured PWT in control (8-week-old) and aging (12-monthold) female mice. We found that PWTs were significantly lower in aging mice compared to control mice in vehicle treated groups, indicating that aging mice exhibit mechanical allodynia. In the aging mice, PWTs declined slightly with time in vehicle group, but increased significantly in L-TAMS-treated group, indicating that oral L-TAMS may reverse the mechanical allodynia in aging mice (Fig. 1C). To confirm the results and investigate the underlying mechanisms, we recorded the $\mathrm{C}$-fiber evoked field potentials in spinal dorsal horn following the behavioral tests and calculated the stimulus-response curves. As shown in Fig.

$1 \mathrm{D}$ and $\mathrm{E}$, the curves were shifted rightwards in both OVX and aging mice treated with vehicle, and changes were significantly smaller in the OVX and aging mice treated with L-TAMS. L-TAMS had no effect on sham and control mice. The data suggest that synaptic transmission in C-fiber synapses is potentiated in OVX and aging mice, and the potentiation is depressed by oral L-TAMS.

\section{Oral magnesium-L-Threonate attenuates the memory/emotional deficits in both ovariectomized mice and aging female mice}

In consistence with the clinical data showing memory deficits in menopause women [4], we found that the memory function was impaired in OVX and aging mice, as in vehicle-treated groups, recognition index assessed by NORT and alternation index assessed by Y-maze in both OVX mice and aging mice were significantly lower than those in sham mice and control mice, respectively (Fig. 2A and B). Interestingly, we found that both indexes were significantly higher in OVX and aging mice treated with L-TAMS than those treated with vehicle (Fig. 2A and B), while no difference was detected in sham and control mice between vehicle- and L-TAMS-treated groups. Thus, the memory function in OVX and aging mice but not in sham and control mice was substantially improved by oral L-TAMS. We found that in OVX and aging mice treated with vehicle, the immobility time assessed by both FST and TST was significantly higher compared to sham and control mice, and the change was substantially reduced in L-TAMS-treated groups 
(Fig. $2 \mathrm{C}$ and $\mathrm{D}$ ). The results indicate that oral L-TAMS also attenuates the depression-like behaviors induced by OVX and aging.

As no difference in the pain hypersensitivity (Fig. 1), memory function and emotional behaviors (Fig. 2) between control and sham mice were detected, in following experiments, the data from the two groups were pooled together.

\section{Oral L-TAMS depresses the neuroinflammation in dorsal root ganglion and in spinal dorsal horn in ovariectomized and aging mice}

Previous works show that neuroinflammation in pain pathway, characterized by activation of TNF-a/NFKB pathway and glial activation, play key roles in development of persistent pain induced by peripheral nerve injury [38, 39], chemotherapy [18, 19] and high frequency noxious stimulation [6]. We, therefore, tested if oral L-TAMS is capable of depressing the neuroinflammation in dorsal root ganglion (DRG) and spinal dorsal horn in ovariectomized and aging mice. We found that levels of phospho-p65 ( $p$-p65, an active form of NF-KB, Fig. 3A), TNF-a (Fig. 3B) and IL-1 3 (Fig. 3C) in DRG neurons were significantly higher in OVX and aging mice compared to sham mice, and the changes were substantially prevented by oral L-TAMS (Fig. 3D). L-TAMS had no effect in sham mice.

The western blots with spinal dorsal horn tissue showed that $p$-p65, TNF- $\alpha$ and IL-1 $\beta$ were significantly upregulated in both OVX (Figs. 3A and C) and aging female mice (Figs. 3B and D) compared to sham mice treated with vehicle. The molecular changes were, again, substantially attenuated by oral L-TAMS (Figs. 3A-D). Double immunostaining revealed that $p$-p65 and TNF-a were heavily co-localized with NeuN (a marker for neuron), sparsely with Iba1 (a marker for microglial cell) and GFAP (a marker for astrocyte) (Figs. 3E and F). Interestingly, IL-1 $\beta$ was co-localized with IB4 (a marker for non-peptidergic C-fibers) and CGRP (a marker for peptidergic C-fibers) in superficial spinal dorsal horn (Fig. 4H), sparsely with GFAP and Iba1, but not with NeuN (Figs. 4G). We found that both microglia and astrocytes were activated in OVX and aging female mice treated with vehicle, as both intensities of Iba 1 and GFAP, and the numbers of Iba1- and GFAP-positive cells were significantly increased in these mice, compared to sham ones (Figs. $5 A-F)$. The glial activation in OVX and aging mice was remarkedly prevented or reversed by L-TAMS.

Our previous works show that chemotherapy [17] and higher frequency noxious stimuli[6] that induce persistent pain increases the peptidergic terminals in spinal dorsal horn. We found that in OVX and aging mice the CGRP-positive but not IB4-positive C-fibers were also increased in the spinal dorsal horn, and oral application of L-TAMS prevented and reversed the CGRP upregulation in OVX mice and aging mice, respectively (Figs. 6A-D). Western blots confirmed that oral L-TAMS depressed the increase in CGRP terminals (Figs. $6 \mathrm{E}, \mathrm{H}$ ).

\section{Oral L-TAMS depresses the neuroinflammation in hippocampi of ovariectomized and aging mice}

As neuroinflammation plays a key role in memory and emotional deficits in a variety of disease models, such as peripheral nerve injury [8], chemotherapy [18, 19], Alzheimer disease [40], and mood depression 
$[41,42]$, we next investigated if the neuroinflammation also exists in hippocampi of OVX and aging mice. We found that the $p$-p65, TNF- $\alpha$ and IL-1 $\beta$ in the hippocampi were significantly higher in both OVX and aging female mice than those in sham mice in vehicle-treated groups, and the changes were significantly attenuated by oral L-TAMS (Figs. 7A-D). Double immunostainings (Figs. 7E-G) showed that $p$-p65, TNF-a or IL-1 $\beta$ was mainly co-localized with NeuN, sparsely with Iba1 and GFAP. We found that both intensities of Iba1 and GFAP, and the numbers of Iba1- and GFAP-positive cells in hippocampi were significantly increased in both OVX and aging mice, compared to sham mice in vehicle-treated groups (Figs. 8A-D). Interestingly, we found that the glial activation induced by OVX or aging was, again, remarkedly prevented and reversed by oral L-TAMS (Figs. 8A-D). The data suggest that oral L-TAMS may attenuate the memory and emotional deficits in OVX and old mice by inhibition of neuroinflammation.

\section{The estrogen decline causes neuroinflammation through producing magnesium deficiency in ovariectomized and aging female mice}

Clinical data show that serum $\mathrm{Mg}^{2+}$ is decreased in postmenopausal women [12, 13]. Our data demonstrated that supplement $\mathrm{Mg}^{2+}$ by chronic oral application of L-TAMS substantially attenuated the chronic pain sensitivity, memory/emotional deficits as well as neuroinflammation induced by either OVX or aging. We, therefore, hypothesized that estrogen decline may cause neuroinflammation by producing $\mathrm{Mg}^{2+}$ deficiency. To test this, we first determine if $\mathrm{Mg}^{2+}$ is really reduced in OVX and old mice. We found that free $\mathrm{Mg}^{2+}$ in serum and in CSF was significantly lower in both OVX and aging mice in vehicle-treated groups (Figs. $9 \mathrm{~A}$ and B). As $31 \%$ of $\mathrm{Mg}^{2+}$ in the body is distributed inside cells, where it functions as a coactivator for 600 enzymes [24], the change in intracellular $\mathrm{Mg}^{2+}$ is more important for cell function. To determine if the intracellular $\mathrm{Mg}^{2+}$ is also reduced in the neuronal cells, we measured intracellular free $\mathrm{Mg}^{2+}$ in DRG neurons, and found that the ion was also significantly lower in OVX and old mice, compared to sham mice (Fig. 9C). The extracellular and intracellular $\mathrm{Mg}^{2+}$ deficiency induced by OVX and aging was attenuated by oral L-TAMS (Fig. 9A-C). We found that the concentration of plasma estrogen was $18.8 \pm 3.3 \mathrm{ng} / \mathrm{L}$ in sham mice, and is decreased significantly in OVX and aging mice. Oral L-TAMS did not affect plasma estrogen levels in sham, OVX and aging mice (Fig. 9D). To exam if the $\mathrm{Mg}^{2+}$ deficiency is directly caused by estrogen decline, we cultured DRG neurons with different concentrations of estrogen, and found that estrogen at 20 but not $5 \mathrm{ng} / \mathrm{ml}$ significantly enhanced the intracellular free $\mathrm{Mg}^{2+}$ (Fig. 10A). That is, intracellular $\mathrm{Mg}^{2+}$ is regulated by extracellular estrogen. Finally, we determined if estrogen decline might activate TNF- $\alpha$ /NF-KB pathway via producing $\mathrm{Mg}^{2+}$ deficiency in cultured DRG neurons. As shown in Figs. $10 \mathrm{~B}$ and $\mathrm{D}$, in culture medium that containing $\mathrm{Mg}^{2+}(0.7 \mathrm{mM})$, estrogen at $20 \mathrm{ng} / \mathrm{L}$ but not $5 \mathrm{ng} / \mathrm{L}$ downregulated $p$-p65, TNF- $\alpha$ and IL-1 $\beta$. While in magnesium free medium estrogen had no such effect at either of doses. The data demonstrate that $\mathrm{Mg}^{2+}$ deficiency play a key role in estrogen declineinduced neuroinflammation.

\section{Discussion}


In the present work, we found that the chronic pain hypersensitivity, memory decline, depression-like behaviors in OVX and aging mice were substantially prevented or reversed by chronic oral administration of L-TAMS (Figs. 1, 2). Then, we showed that OVX- and aging-induced neuroinflammation, manifested as upregulation of $p$-p65, TNF-a, IL-1 $\beta$, and glial activation, was associated with extracellular and intracellular $\mathrm{Mg}^{2+}$ deficiency. Both of them were significantly attenuated by oral L-TAMS (Figs. 3-5, 7-8). Finally, we exposed that estrogen decline induced neuroinflammation by reducing intracellular $\mathrm{Mg}^{2+}$ deficiency in cultured DRG neurons (Figs. 9-10). Together, estrogen decline causes neuroinflammation by reducing intracellular $\mathrm{Mg}^{2+}$, leading to the neuronal disorders. Chronic oral application of L-TAMS may be a novel approach for treating menopause-related neuronal disorders.

\section{The treatment for menopause-related chronic pain and memory/emotional deficits}

Hormone replace therapy (HRT) with estrogen is used to treat muscular pain [43], cognitive impairment [4, $44]$ and mood depression $[45,46]$ in menopause women. The HRT has been vigorously debated, since its first use in 1940s. Earlier data show that HRT reduces coronary heart disease and mortality, while the later randomized trials in older women (aged $>60$ years) showed it had no such effect (see [47] for a review). A recent systematic review indicates that long-term HRT increases the risks of thromboembolic disease, breast cancer and endometrial cancer, and is not indicated for prevention of cardiovascular disease, dementia or deterioration of cognitive function in postmenopausal women [48]. Therefore, the benefit of HRT for menopause symptom might be limited.

Clinical data show that IL-1 and TNF-a in plasma elevate in women with both OVX [49] and menopause [50]. Accumulative experimental evidence has demonstrated that the overproduction of these inflammatory cytokines is necessary and even sufficient to induce chronic pain, memory decline and mood depression in rodents $[8,9,51,52]$. It has been proposed that the estrogen decline-induced neuronal disorders are mediated by inflammation [11]. While how estrogen decline causes inflammation in the nervous system remains unclear. In the present work, we showed that free $\mathrm{Mg}^{2+}$ in extracellular fluids (serum and CSF) and inside neurons was reduced in OVX and aging mice. Importantly, we revealed for the first time that $\mathrm{Mg}^{2+}$ deficiency is critical for estrogen decline-induced upregulation of $p$-p65, TNF-a and IL-1 $\beta$ in cultured DRG neurons. Supplement $\mathrm{Mg}^{2+}$ by oral L-TAMS substantially prevented or reversed neuroinflammation, and chronic pain, memory decline and depression-like behaviors in OVX and aging mice. Therefore, supplement $\mathrm{Mg}^{2+}$ may be an alternative or even better treatment for menopause symptom.

\section{The role of increased peptidergic C-fibers in spinal dorsal horn in chronic pain}

The increase in CGRP-positive peptidergic C-fibers in spinal dorsal horn has been demonstrated in many animal models of chronic pain, including chemotherapy [17], spinal cord injury [53], higher frequency noxious stimulation of peripheral nerve [6]. In this present work we found that the peptidergic C-fibers were also increased in spinal dorsal horn in OVX and in aging mice. Importantly, the change is paralleled with synaptic potentiation mediated by $\mathrm{C}$-fibers and chronic pain hypersensitivity. The data suggest that 
the morphological change may serve as a structural basis for different forms of chronic pain. Interestingly, we showed that the peptidergic C-fibers express IL-1 $\beta$ and oral L-TAMS, which inhibits IL-1 $\beta$, substantially prevented the increase in the peptidergic $\mathrm{C}$-fibers induced by OVX and aging, indicating that neuroinflammation may play a role in the morphological change. Further studies are needed to clarify the pathological meaning of the structural change and underlying mechanisms.

\section{The approaches for treating the inflammation-related chronic diseases}

Compelling evidence demonstrates that inflammation plays a key role in many, if not all, chronic diseases [54]. While the treatment of the inflammation remains a big challenge in clinical practice. Inflammation has many physiological functions, such as protecting the host from infections by bacteria and viruses, and promoting tissue repair and recovery $[55,56]$. In the nervous system TNF- $\mathrm{a} / \mathrm{NF}-\mathrm{KB}$ signaling is important for memory storage [57]. Microglia and astrocytes are crucial for regulating neuronal structures and activities [58] and neurogenesis [59]. Thus, normal inflammation response is essential. However, excessive inflammation, such as neuroinflammation i.e., persistent overproduction of inflammatory cytokines and glial activation play key roles in neuropathic pain [39], Alzheimer's disease [40] and depression $[41,42]$. Therefore, the correct stratagem for treating inflammation-related diseases is to bring it back to normal level. This is difficult to achieve using the agents that inhibit inflammatory cytokine and glial activation. It has been shown that $\mathrm{Mg}^{2+}$ deficiency contribute to many inflammation-related chronic diseases, such as hypertension, ischemic heart disease, stroke, metabolic syndrome, diabetes and colorectal cancer [60]. Our previous works show that antineoplastic agents (vincristine oxaliplatin and cyclophosphamide) induce neuroinflammation, and chronic pain, memory decline and depression-like behaviors via producing $\mathrm{Mg}^{2+}$ deficiency [17-19]. In this present work we further showed that $\mathrm{Mg}^{2+}$ deficiency did the same in animal models of menopause. Together, $\mathrm{Mg}^{2+}$ deficiency plays a key role in persistent inflammation and chronic diseases. Accordingly, supplementary $\mathrm{Mg}^{2+}$ can bring the inflammation back to but never below normal level. We used L-TAMS to supplement $\mathrm{Mg}^{2+}$, because a previous work [20] show that only L-TAMS but not other magnesium compounds $\left(\mathrm{MgCl}_{2}, \mathrm{Mg}\right.$ citrate, $\mathrm{Mg}$ gluconate) is able to elevate $\mathrm{Mg}^{2+}$ in the CSF of rats. Increasing the plasma $\mathrm{Mg}^{2+}$ by three-fold via intravenous infusion of $\mathrm{MgSO}_{4}$ does not elevate $\mathrm{Mg}^{2+}$ in the CSF in human patients. [61].

\section{Conclusion}

The neuroinflammation resulting from $\mathrm{Mg}^{2+}$ deficiency contributes to the chronic pain hypersensitivity, memory and emotional deficits induced by OVX and aging. Supplementary $\mathrm{Mg}^{2+}$ by chronic oral L-TAMS is effective for attenuation of the neuroinflammation and neuronal disorders induced by estrogen decline.

\section{Abbreviations}

L-TAMS: magnesium-L-threonate; OVX: ovariectomy; p-p65: phospho-p65; NF-кB: nuclear factor-kappaB; TNF-a: tumor necrosis factor-alpha; IL-1 $\beta$ : interleukin-1beta; DRG: dorsal root ganglion; PWT: paw 
withdrawal threshold; CPP: conditioned place preference; NORT: covel object-recognition test; FST: forced swimming test; TST: tail suspension test; IntDen: integrated density; CSF: cerebrospinal fluid; CGRP: calcitonin gene-related peptide; IB4: isolectin $\mathrm{B}_{4} ; \mathrm{HRT}$ : hormone replace therapy

\section{Declarations}

\section{Acknowledgment}

The study was supported by the National Natural Science Foundation of China (31771166 to XGL).

\section{Authors' contributions}

Xian-Guo Liu designed and supervised this study. Jun Zhang, Chun-Lin Mai and Ying Xiong conducted the majority of the experiments and completed the manuscript. Zhen-Jia Lin, Ying-Tao Jie, Jie-Zhen Mai and Chong Liu participated the behavioral tests. Xin Zhou and Man-Xiu Xie analyzed the data and assisted the manuscript writing. All authors approved the final version of the manuscript.

\section{Funding}

The study was supported by the National Natural Science Foundation of China (31771166 to XGL).

\section{Availability of data and materials}

The data generated during this study are available from the corresponding author on reasonable request.

\section{Ethics approval and consent to participate}

All experimental protocols and animal handling procedures were approved by the Animal Care Committee of Sun Yat-sen University.

\section{Consent for publication}

Not applicable.

\section{Competing interests}

The authors claim that there are no conflicts of interest.

\section{References}

1. Szoeke CE, Cicuttini FM, Guthrie JR, Dennerstein L: The relationship of reports of aches and joint pains to the menopausal transition: a longitudinal study. Climacteric 2008, 11:55-62.

2. Gibson CJ, Li Y, Bertenthal D, Huang AJ, Seal KH: Menopause symptoms and chronic pain in a national sample of midlife women veterans. Menopause 2019, 26:708-713. 
3. Lu CB, Liu PF, Zhou YS, Meng FC, Qiao TY, Yang XJ, Li XY, Xue Q, Xu H, Liu Y, et al: Musculoskeletal Pain during the Menopausal Transition: A Systematic Review and Meta-Analysis. Neural Plast 2020, 2020:8842110.

4. Luine VN: Estradiol and cognitive function: past, present and future. Horm Behav 2014, 66:602-618.

5. Soares CN: Depression and Menopause: An Update on Current Knowledge and Clinical Management for this Critical Window. Med Clin North Am 2019, 103:651-667.

6. Zhou LJ, Peng J, Xu YN, Zeng WJ, Zhang J, Wei X, Mai CL, Lin ZJ, Liu Y, Murugan M, et al: Microglia Are Indispensable for Synaptic Plasticity in the Spinal Dorsal Horn and Chronic Pain. Cell Rep 2019, 27:3844-3859 e3846.

7. Ren WJ, Liu Y, Zhou LJ, Li W, Zhong Y, Pang RP, Xin WJ, Wei XH, Wang J, Zhu HQ, et al: Peripheral nerve injury leads to working memory deficits and dysfunction of the hippocampus by upregulation of TNF-alpha in rodents. Neuropsychopharmacology 2011, 36:979-992.

8. Liu Y, Zhou LJ, Wang J, Li D, Ren WJ, Peng J, Wei X, Xu T, Xin WJ, Pang RP, et al: TNF-alpha Differentially Regulates Synaptic Plasticity in the Hippocampus and Spinal Cord by MicrogliaDependent Mechanisms after Peripheral Nerve Injury. J Neurosci 2017, 37:871-881.

9. Gui WS, Wei X, Mai CL, Murugan M, Wu LJ, Xin WJ, Zhou LJ, Liu XG: Interleukin-1 beta overproduction is a common cause for neuropathic pain, memory deficit, and depression following peripheral nerve injury in rodents. Mol Pain 2016, 12.

10. Mai CL, Tan Z, Xu YN, Zhang JJ, Huang ZH, Wang D, Zhang H, Gui WS, Zhang J, Lin ZJ, et al: CXCL12-mediated monocyte transmigration into brain perivascular space leads to neuroinflammation and memory deficit in neuropathic pain. Theranostics 2021, 11:1059-1078.

11. Au A, Feher A, McPhee L, Jessa A, Oh S, Einstein G: Estrogens, inflammation and cognition. Front Neuroendocrinol 2016, 40:87-100.

12. Reginster JY, Strause L, Deroisy R, Lecart MP, Saltman P, Franchimont P: Preliminary report of decreased serum magnesium in postmenopausal osteoporosis. Magnesium 1989, 8:106-109.

13. Steidl L, Ditmar R: Blood magnesium, calcium and zinc in osteoporosis. Acta Univ Palacki Olomuc Fac Med 1991, 129:91-98.

14. Turner RT, Vandersteenhoven JJ, Bell NH: The effects of ovariectomy and 17 beta-estradiol on cortical bone histomorphometry in growing rats. J Bone Miner Res 1987, 2:115-122.

15. Mazur A, Maier JA, Rock E, Gueux E, Nowacki W, Rayssiguier Y: Magnesium and the inflammatory response: potential physiopathological implications. Arch Biochem Biophys 2007, 458:48-56.

16. Serefko A, Szopa A, Poleszak E: Magnesium and depression. Magnes Res 2016, 29:112-119.

17. Xu T, Li D, Zhou X, Ouyang HD, Zhou LJ, Zhou H, Zhang HM, Wei XH, Liu G, Liu XG: Oral Application of Magnesium-L-Threonate Attenuates Vincristine-induced Allodynia and Hyperalgesia by Normalization of Tumor Necrosis Factor-alpha/Nuclear Factor-kappaB Signaling. Anesthesiology 2017, 126:1151-1168. 
18. Zhou X, Huang Z, Zhang J, Chen JL, Yao PW, Mai CL, Mai JZ, Zhang H, Liu XG: Chronic Oral Administration of Magnesium-L-Threonate Prevents Oxaliplatin-Induced Memory and Emotional Deficits by Normalization of TNF-a/NF-KB Signaling in Rats. Neurosci Bull 2020.

19. Chen JL, Zhou X, Liu BL, Wei XH, Ding HL, Lin ZJ, Zhan HL, Yang F, Li WB, Xie JC, et al: Normalization of magnesium deficiency attenuated mechanical allodynia, depressive-like behaviors, and memory deficits associated with cyclophosphamide-induced cystitis by inhibiting TNF-alpha/NF-kappaB signaling in female rats. J Neuroinflammation 2020, 17:99.

20. Slutsky I, Abumaria N, Wu LJ, Huang C, Zhang L, Li B, Zhao X, Govindarajan A, Zhao MG, Zhuo M, et al: Enhancement of learning and memory by elevating brain magnesium. Neuron 2010, 65:165-177.

21. Ying YL, Wei XH, Xu XB, She SZ, Zhou LJ, Lv J, Li D, Zheng B, Liu XG: Over-expression of P2X7 receptors in spinal glial cells contributes to the development of chronic postsurgical pain induced by skin/muscle incision and retraction (SMIR) in rats. Exp Neurol 2014, 261:836-843.

22. Wang J, Liu Y, Zhou LJ, Wu Y, Li F, Shen KF, Pang RP, Wei XH, Li YY, Liu XG: Magnesium L-threonate prevents and restores memory deficits associated with neuropathic pain by inhibition of TNF-alpha. Pain Physician 2013, 16:E563-575.

23. Liu G, Weinger JG, Lu ZL, Xue F, Sadeghpour S: Efficacy and Safety of MMFS-01, a Synapse Density Enhancer, for Treating Cognitive Impairment in Older Adults: A Randomized, Double-Blind, PlaceboControlled Trial. J Alzheimers Dis 2016, 49:971-990.

24. Gile J, Ruan G, Abeykoon J, McMahon MM, Witzig T: Magnesium: The overlooked electrolyte in blood cancers? Blood Rev 2020:100676.

25. Li W, Yu J, Liu Y, Huang X, Abumaria N, Zhu Y, Huang X, Xiong W, Ren C, Liu XG, et al: Elevation of brain magnesium prevents synaptic loss and reverses cognitive deficits in Alzheimer's disease mouse model. Mol Brain 2014, 7:65.

26. Sophocleous A, Idris AJBr: Rodent models of osteoporosis. 2014, 3:614.

27. Lasota A, Danowska-Klonowska DJRAMwB: Experimental osteoporosis-different methods of ovariectomy in female white rats. 2004:129-131.

28. Chaplan SR, Bach FW, Pogrel JW, Chung JM, Yaksh TL: Quantitative assessment of tactile allodynia in the rat paw. $J$ Neurosci Methods 1994, 53:55-63.

29. King T, Vera-Portocarrero L, Gutierrez T, Vanderah TW, Dussor G, Lai J, Fields HL, Porreca F: Unmasking the tonic-aversive state in neuropathic pain. Nat Neurosci 2009, 12:1364-1366.

30. Ennaceur A, Delacour JJBbr: A new one-trial test for neurobiological studies of memory in rats. 1: Behavioral data. 1988, 31:47-59.

31. Lalonde R: The neurobiological basis of spontaneous alternation. Neurosci Biobehav Rev 2002, 26:91-104.

32. Detke MJ, Rickels M, Lucki l: Active behaviors in the rat forced swimming test differentially produced by serotonergic and noradrenergic antidepressants. Psychopharmacology (Berl) 1995, 121:66-72. 
33. Porsolt R, Bertin A, Jalfre MJAidpedt: Behavioral despair in mice: a primary screening test for antidepressants. 1977, 229:327-336.

34. Steru L, Chermat R, Thierry B, Simon PJP: The tail suspension test: a new method for screening antidepressants in mice. 1985, 85:367-370.

35. Liu X, Sandkühler JJNI: Long-term potentiation of C-fiber-evoked potentials in the rat spinal dorsal horn is prevented by spinal N-methyl-D-aspartic acid receptor blockage. 1995, 191:43-46.

36. Chen X, Pang R, Shen K, Zimmermann M, Xin W, Li Y, Liu XJEn: TNF-a enhances the currents of voltage gated sodium channels in uninjured dorsal root ganglion neurons following motor nerve injury. 2011, 227:279-286.

37. Abernethy M, Fowler RJCc: Micellar improvement of the calmagite compleximetric measurement of magnesium in plasma. 1982, 28:520-522.

38. Xu JT, Xin WJ, Zang Y, Wu CY, Liu XG: The role of tumor necrosis factor-alpha in the neuropathic pain induced by Lumbar 5 ventral root transection in rat. Pain 2006, 123:306-321.

39. Ellis A, Bennett DL: Neuroinflammation and the generation of neuropathic pain. Br J Anaesth 2013, 111:26-37.

40. Calsolaro V, Edison P: Neuroinflammation in Alzheimer's disease: Current evidence and future directions. Alzheimers Dement 2016, 12:719-732.

41. Benedetti F, Aggio V, Pratesi ML, Greco G, Furlan R: Neuroinflammation in Bipolar Depression. Front Psychiatry 2020, 11:71.

42. Walker AK, Kavelaars A, Heijnen CJ, Dantzer R: Neuroinflammation and comorbidity of pain and depression. Pharmacol Rev 2014, 66:80-101.

43. Watt FE: Musculoskeletal pain and menopause. Post Reprod Health 2018, 24:34-43.

44. Herrera AY, Hodis HN, Mack WJ, Mather M: Estradiol Therapy After Menopause Mitigates Effects of Stress on Cortisol and Working Memory. J Clin Endocrinol Metab 2017, 102:4457-4466.

45. Schmidt PJ, Ben Dor R, Martinez PE, Guerrieri GM, Harsh VL, Thompson K, Koziol DE, Nieman LK, Rubinow DR: Effects of Estradiol Withdrawal on Mood in Women With Past Perimenopausal Depression: A Randomized Clinical Trial. JAMA Psychiatry 2015, 72:714-726.

46. Gordon JL, Rubinow DR, Eisenlohr-Moul TA, Xia K, Schmidt PJ, Girdler SS: Efficacy of Transdermal Estradiol and Micronized Progesterone in the Prevention of Depressive Symptoms in the Menopause Transition: A Randomized Clinical Trial. JAMA Psychiatry 2018, 75:149-157.

47. Lobo RA: Hormone-replacement therapy: current thinking. Nat Rev Endocrinol 2017, 13:220-231.

48. Marjoribanks J, Farquhar C, Roberts H, Lethaby A, Lee J: Long-term hormone therapy for perimenopausal and postmenopausal women. Cochrane Database Syst Rev 2017, 1:Cd004143.

49. Pacifici R, Brown C, Puscheck E, Friedrich E, Slatopolsky E, Maggio D, McCracken R, Avioli LV: Effect of surgical menopause and estrogen replacement on cytokine release from human blood mononuclear cells. Proc Natl Acad Sci U S A 1991, 88:5134-5138. 
50. Pfeilschifter J, Köditz R, Pfohl M, Schatz H: Changes in proinflammatory cytokine activity after menopause. Endocr Rev 2002, 23:90-119.

51. Mai CL, Wei X, Gui WS, Xu YN, Zhang J, Lin ZJ, Tan Z, Meng YT, Li YY, Zhou LJ, Liu XG: Differential regulation of GSK-3beta in spinal dorsal horn and in hippocampus mediated by interleukin-1 beta contributes to pain hypersensitivity and memory deficits following peripheral nerve injury. Mol Pain 2019, 15:1744806919826789.

52. Bakare AO, Owoyele BV: Bromelain reduced pro-inflammatory mediators as a common pathway that mediate antinociceptive and anti-anxiety effects in sciatic nerve ligated Wistar rats. Sci Rep 2021, 11:289.

53. Hou S, Duale H, Rabchevsky AG: Intraspinal sprouting of unmyelinated pelvic afferents after complete spinal cord injury is correlated with autonomic dysreflexia induced by visceral pain. Neuroscience 2009, 159:369-379.

54. Furman D, Campisi J, Verdin E, Carrera-Bastos P, Targ S, Franceschi C, Ferrucci L, Gilroy DW, Fasano A, Miller GW, et al: Chronic inflammation in the etiology of disease across the life span. Nat Med 2019, 25:1822-1832.

55. Netea MG, Balkwill F, Chonchol M, Cominelli F, Donath MY, Giamarellos-Bourboulis EJ, Golenbock D, Gresnigt MS, Heneka MT, Hoffman HM, et al: A guiding map for inflammation. Nat Immunol 2017, 18:826-831.

56. Kotas ME, Medzhitov R: Homeostasis, inflammation, and disease susceptibility. Cel/ 2015, 160:816827.

57. Meffert MK, Baltimore D: Physiological functions for brain NF-kappaB. Trends Neurosci 2005, 28:3743.

58. Kato D, Eto K, Nabekura J, Wake H: Activity-dependent functions of non-electrical glial cells. $J$ Biochem 2018, 163:457-464.

59. Falk S, Götz M: Glial control of neurogenesis. Curr Opin Neurobiol 2017, 47:188-195.

60. Nielsen FH: Dietary Magnesium and Chronic Disease. Adv Chronic Kidney Dis 2018, 25:230-235.

61. McKee JA, Brewer RP, Macy GE, Borel CO, Reynolds JD, Warner DS: Magnesium neuroprotection is limited in humans with acute brain injury. Neurocrit Care 2005, 2:342-351.

\section{Figures}



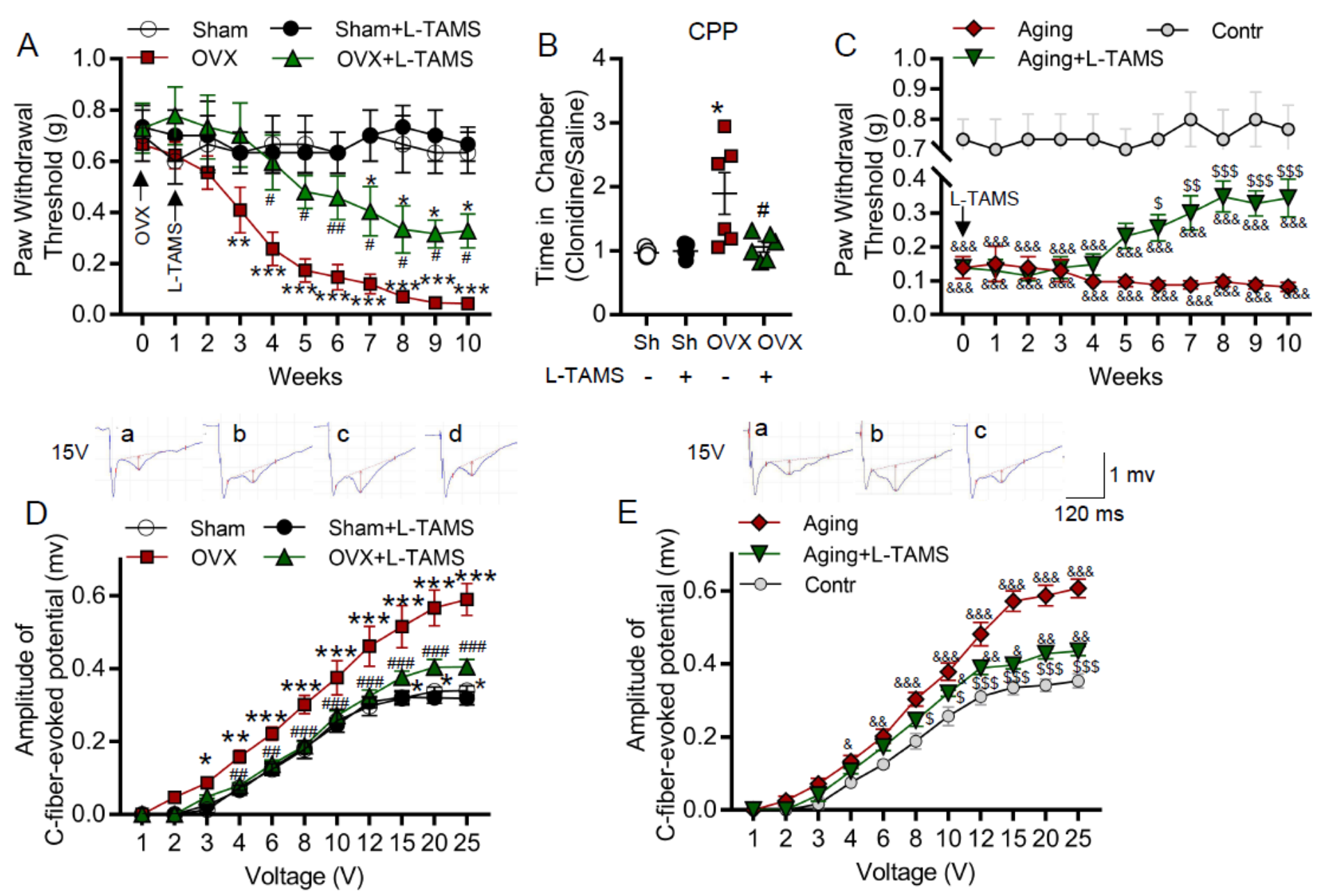

Figure 1

Oral application of L-TAMS attenuates the pain hypersensitivity and potentiation at C-fiber synapses in both ovariectomized and aging female mice. (A) The time courses of paw withdrawal thresholds elicited by von Frey filaments in sham mice treated with vehicle (Sham, $n=6)$, sham mice treated with L-TAMS (Sham + L-TAMS, $n=6)$, ovariectomized mice treated with vehicle (OVX, $n=9)$, and OVX mice treated with L-TAMS (OVX + L-TAMS, n=9) are shown. (B) In the conditioned place preference (CPP) experiment, the ratio of time that mice spent in clonidine paired box and saline paired box were recorded. Treatment with L-TAMS significantly suppressed clonidine induced chamber preference in OVX group $(n=5$ in Sham and Sham + L-TAMS groups, $n=6$ in OVX and in OVX + L-TAMS groups). (C) The time courses of paw withdrawal thresholds in control ( 8 weeks, $n=6)$, aging (12 mouths, $n=10)$ and aging + L-TAMS $(n=10)$ mice are shown. (D) The stimulus-response curves of $C$-fiber evoked potentials in the spinal dorsal horn in different groups as indicated are shown ( $n=6-8$ per groups). Raw traces show the field potentials evoked by $15 \mathrm{~V}$ in Sham (a), Sham + L-TAMS (b), OVX (c), and OVX + L-TAMS (d) groups. The red vertical line represents the amplitude of the $\mathrm{C}$-fiber evoked field potentials. (E) The stimulus-response curves of $\mathrm{C}$-fiber evoked potentials in different groups as indicated are shown ( $n=6-8$ per groups). Raw traces show the field potentials evoked by $15 \mathrm{~V}$ in Control (a), Aging (b) and Aging + L-TAMS (c) groups. The data in A, C, D, E were analyzed by two-way ANOVA with Tukey's test. The data in B were analyzed by one-way ANOVA 


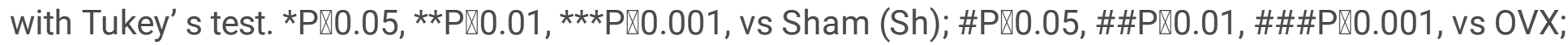
$\& P \llbracket 0.05, \& \& P \llbracket 0.01, \& \& \& P \llbracket 0.001$, vs Contr; $\$ P \rrbracket 0.05$,

$$
P \square 0.01 \text {, }
$$

$\$ P \otimes 0.001$, vs Aging.
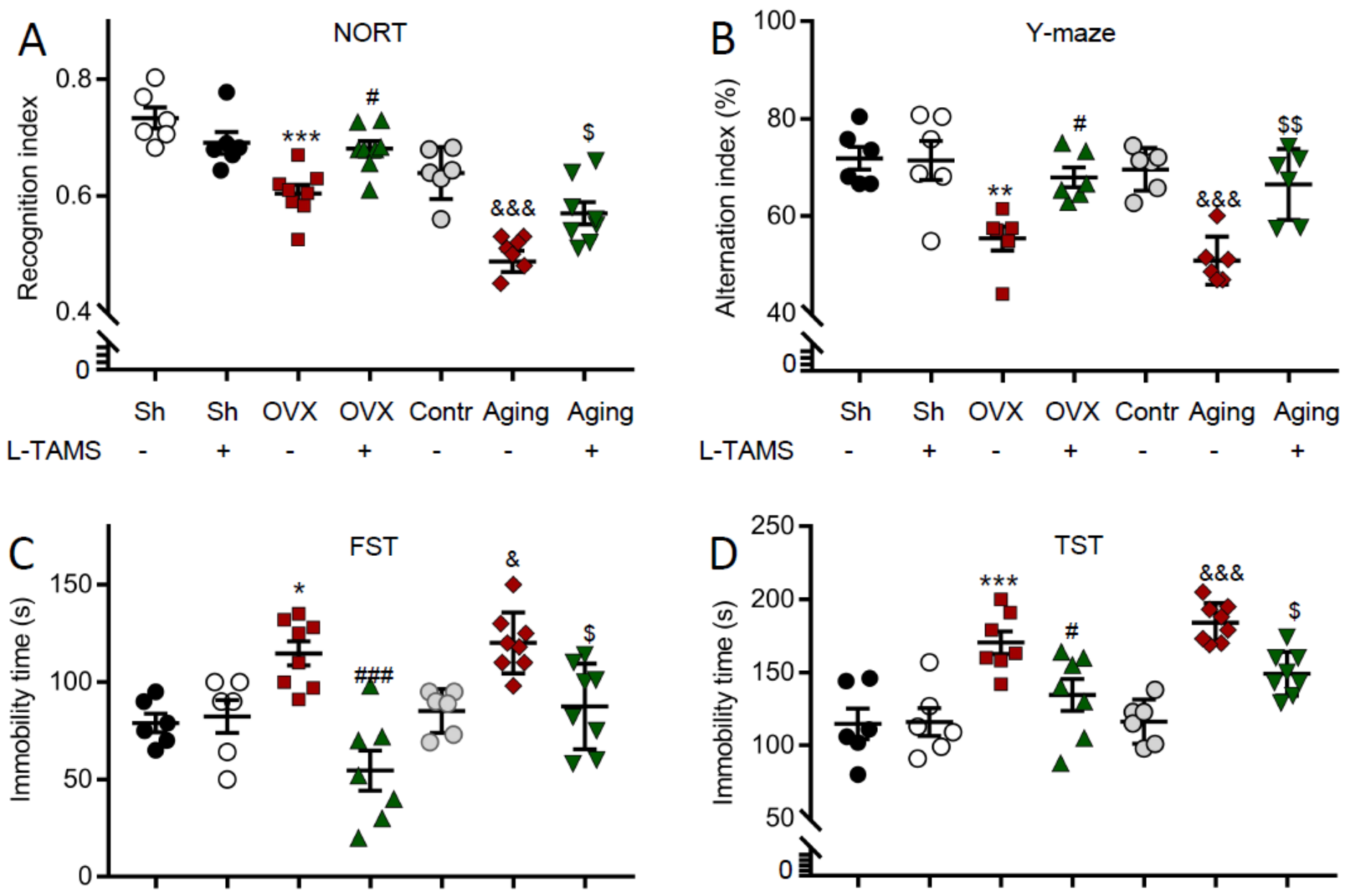

Sh Sh OVX OVX Contr Aging Aging

L-TAMS - $+-+-\quad+\quad+$

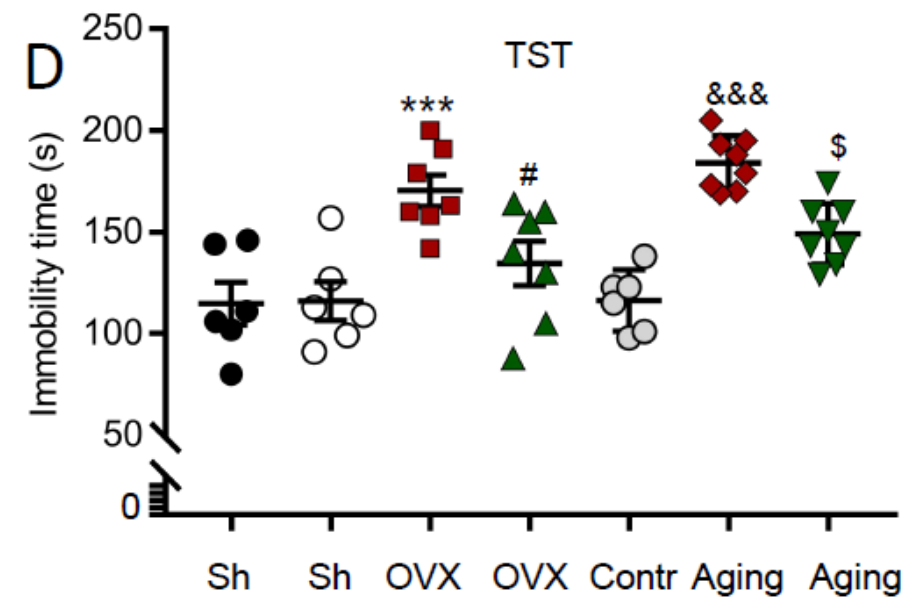

L-TAMS - $+-\quad+\quad-\quad-\quad+$

\section{Figure 2}

Oral application of L-TAMS attenuates the memory/emotional deficits in both ovariectomized and aging female mice. (A) The recognition indexes assessed with novel object recognition test (NORT) in indicated groups are shown ( $n=6-8$ per group). (B) The scatter diagram shows alternation index (\% of total triplet arm entries) measured with the Y-maze test ( $n=6$ per group). ( $C$ and $D)$ Immobility time in each group were measured in the forced swimming test (C) and tail suspension test (D) ( $n=6-8$ per group). The data

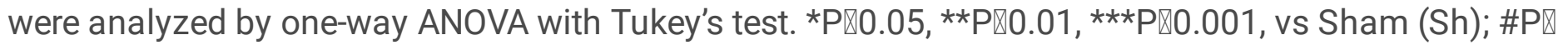

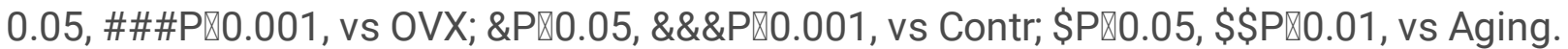


A
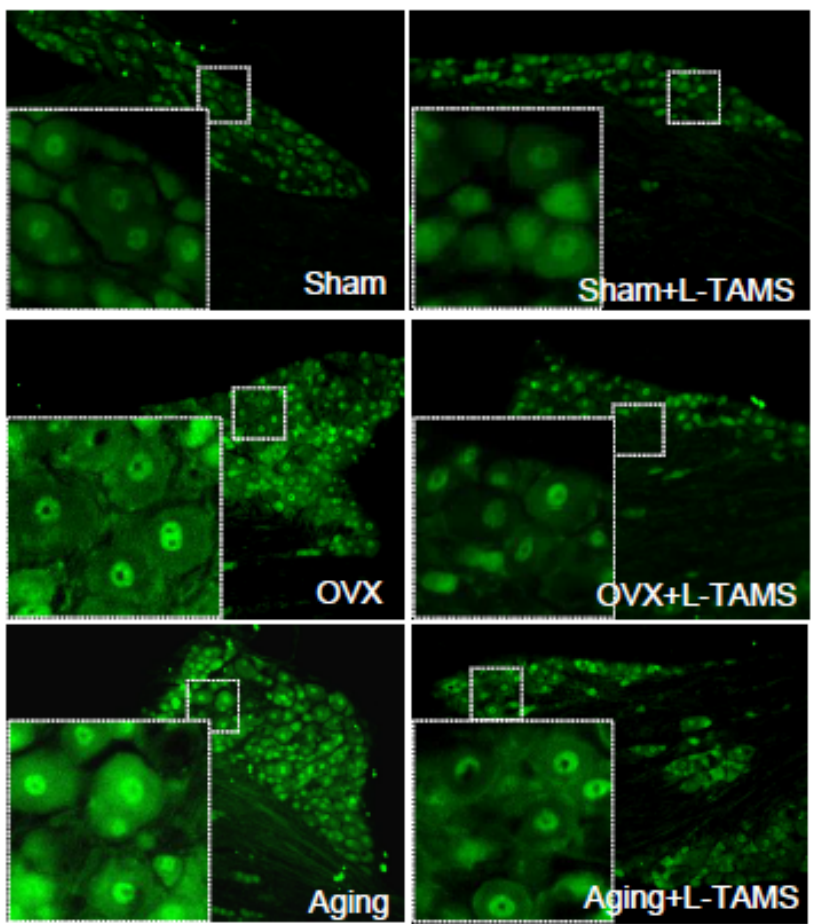

C

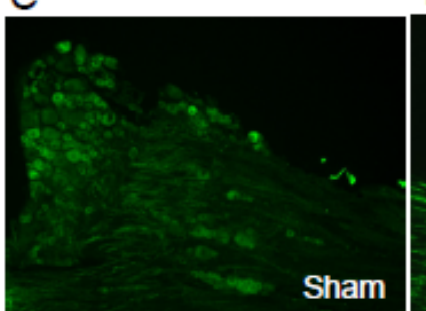

IL-1 $\beta$
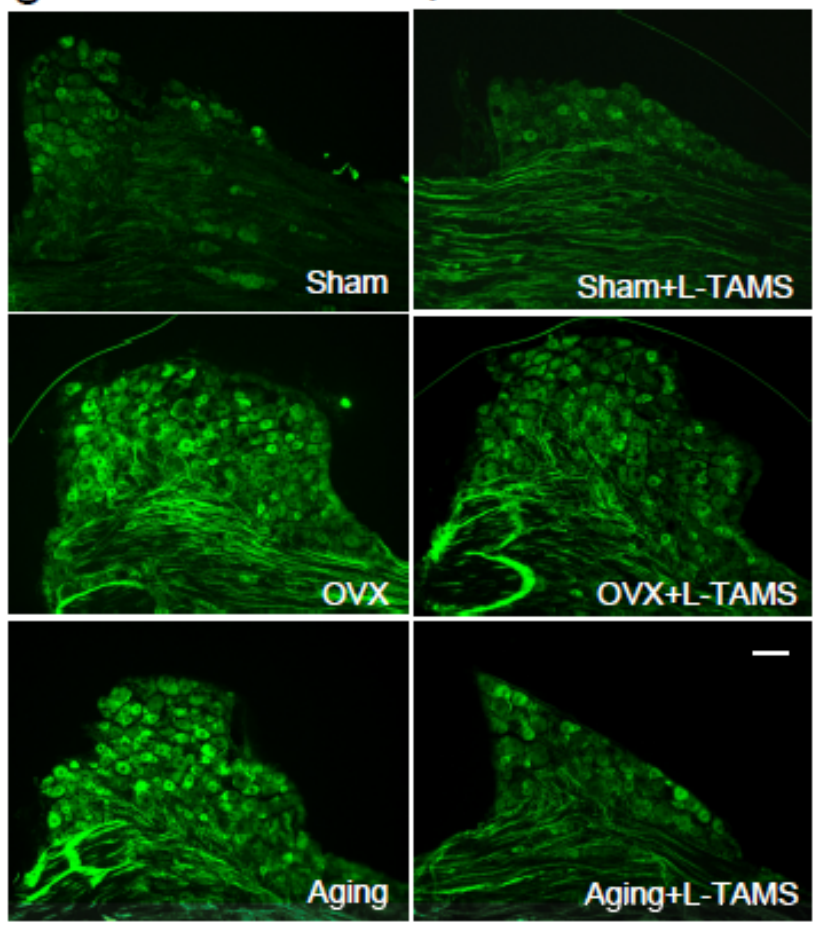

B

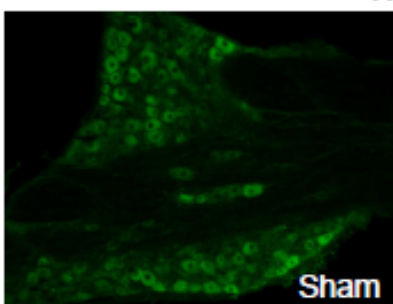

TNF- $\alpha$
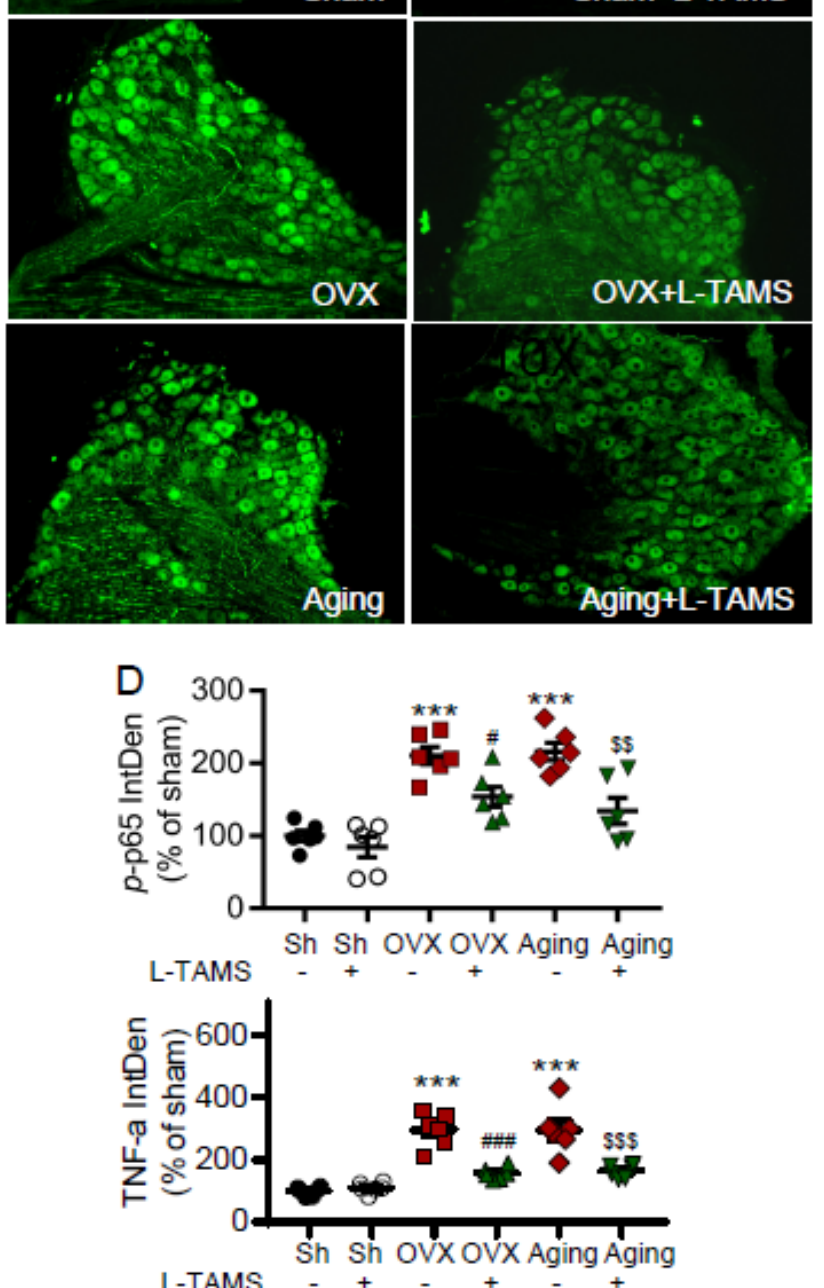

L-TAMS

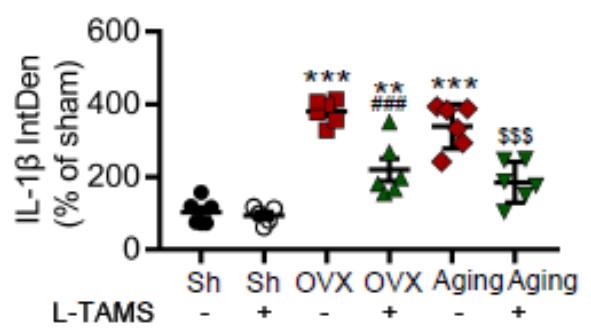

Figure 3

Oral application of L-TAMS attenuates the activation of NF-KB and upregulation of TNF- $\alpha$ and IL-1 $\beta$ in dorsal root ganglion (DRG) neurons of ovariectomized and aging mice. (A-C) Representative immunofluorescent staining images show the expressions of p-p65 (A), TNF- $\alpha$ (B) and IL-1 $\beta$ (C) in DRG neurons in indicated groups. Note: $p-p 65$ is mainly located in nuclei, while TNF- $\alpha$ and IL-1 $\beta$ in cytoplasm and nerve fibers. Scale bar: $100 \mu \mathrm{m}$. (D) Statistical analysis revealed p-p65, TNF- $a$ and IL-1 $\beta$ in DRG 
neurons were upregulated in OVX and aging mice, and the changes were attenuated by oral L-TAMS $(\mathrm{n}=$ 3 mice/group, 2 sections/mouse). The data were analyzed by one-way ANOVA with Tukey's test. **PV

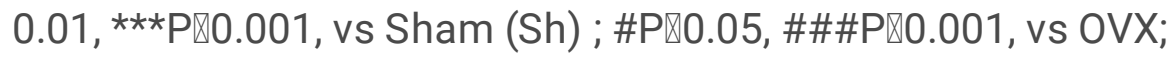

$$
P \square 0.01,
$$

$\$ P \llbracket 0.001$, vs Aging.
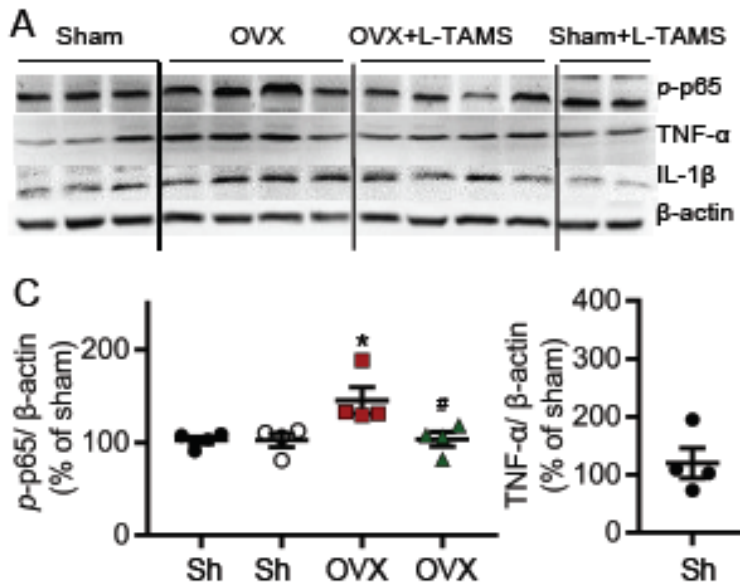

L-TAMS -

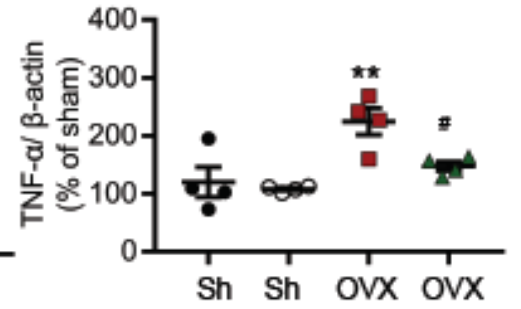

L-TAMS -
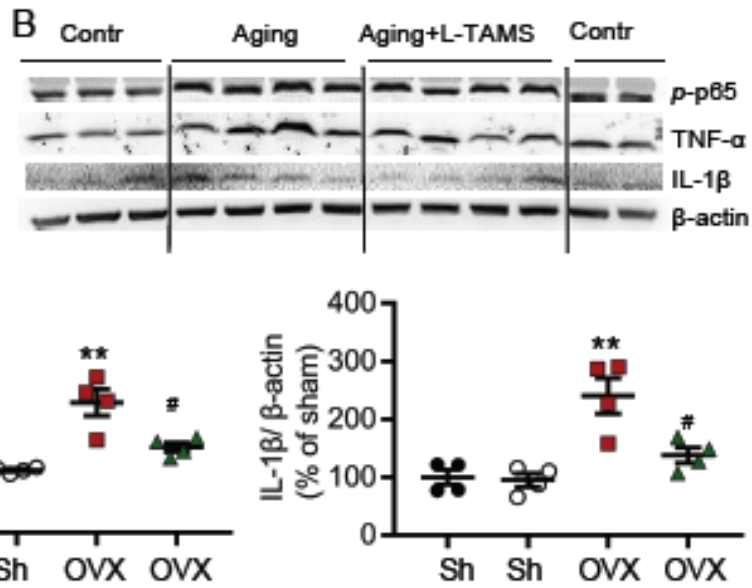

L-TAMS - + - +

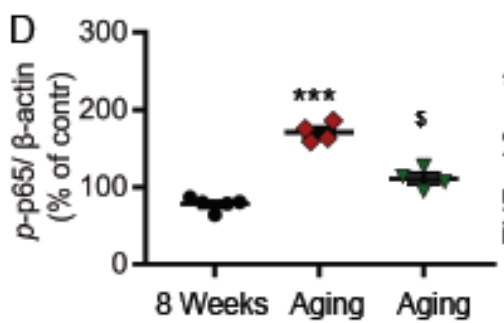
L-TAMS

E
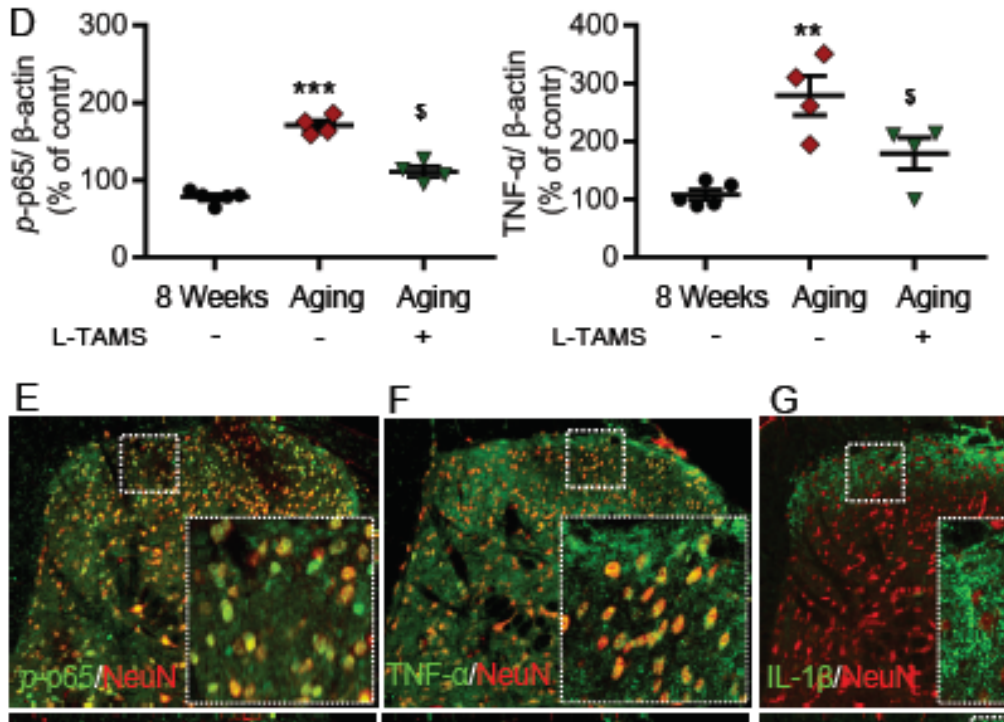

G
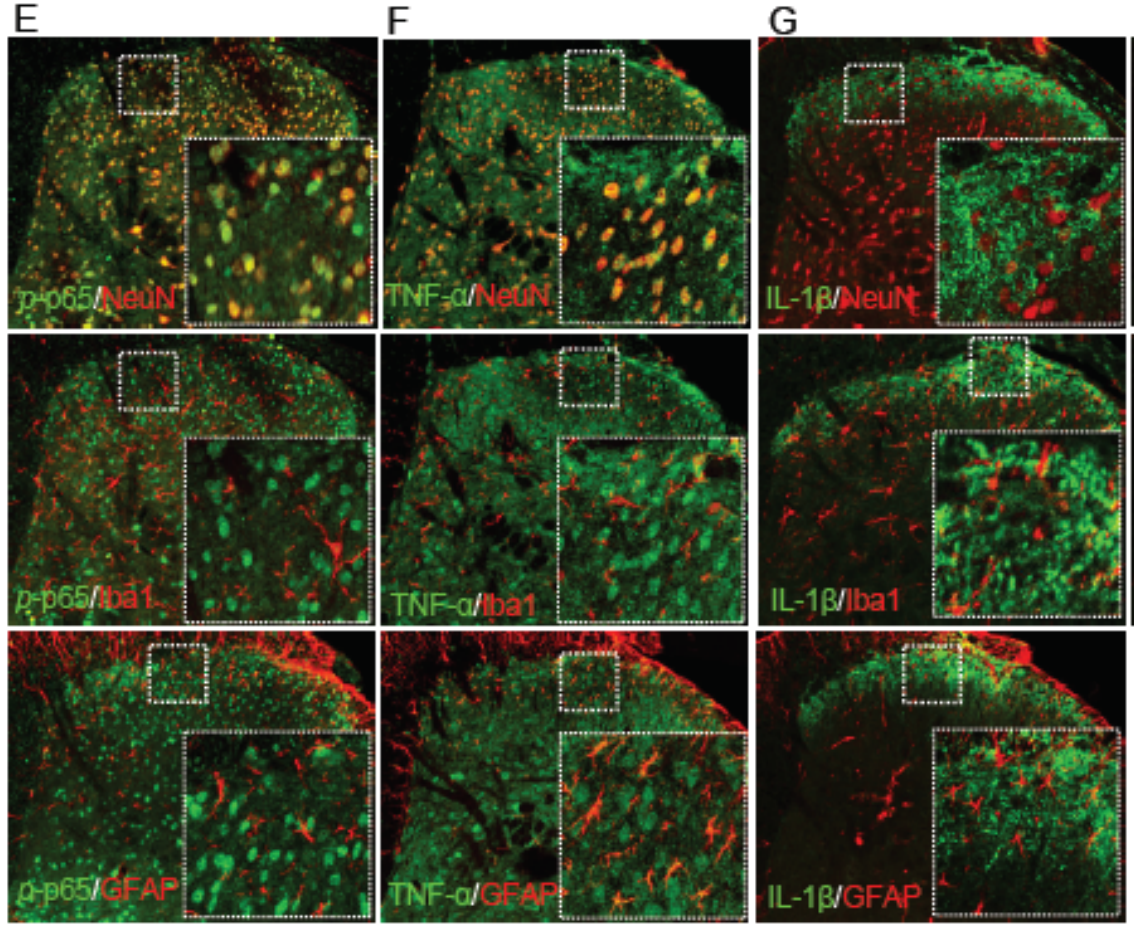

$-1 \beta / G F A P$

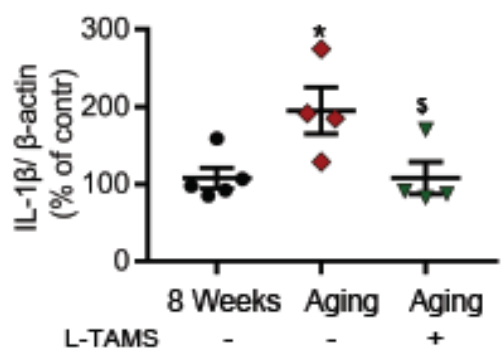

$\mathrm{H}$

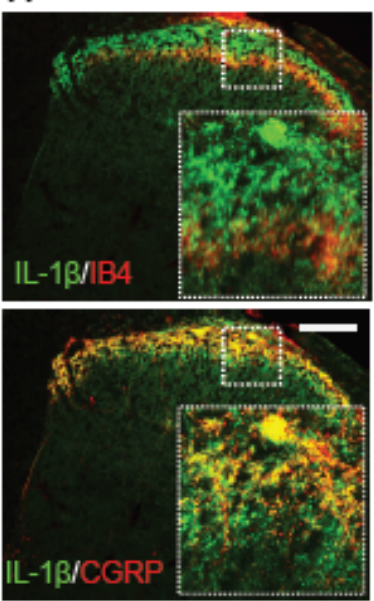

Figure 4 
Oral L-TAMS prevents the activation of NF-KB and upregulation of TNF- $\alpha$ and IL-1 $\beta$ in spinal dorsal horn of ovariectomized and aging mice. (A and $C$ ) Representative Western blots ( $A$ ) and statistical analysis (C) show the protein levels of $p-p 65$, TNF- $\alpha$ and IL-1 $\beta$ in spinal dorsal horn in indicated groups $(n=4$ per group). (B and $D$ ) Representative Western blots (B) and statistical analysis (D) show the levels of $p-p 65$, TNF- $\alpha$, and IL-1 $\beta$ in spinal dorsal horn in control (8 weeks), Aging and Aging + L-TAMS groups $(n=4-5$ per group). The data were analyzed by one-way ANOVA with Tukey's test. ${ }^{*} \mathrm{P} \otimes 0.05,{ }^{\star} * \mathrm{P} \llbracket 0.01,{ }^{\star} \star \star \mathrm{P} \otimes 0.001$, vs Sham (Sh); \#Pख0.05, vs OVX; \$Pख0.05, vs Aging. (E-H) Representative confocal images of the double immunofluorescence staining shows that p-p65 (E) and TNF-a (F) is mainly located in the nuclei and cytoplasm of dorsal horn neurons respectively, they are also expressed in small amounts in microglia (Iba1) and astrocytes (GFAP); The IL-1 $\beta$ ( $G$ and $H$ ) is mainly located in CGRP+ terminals but not in spinal dorsal horn neurons. Scale bar: $100 \mu \mathrm{m}$. 

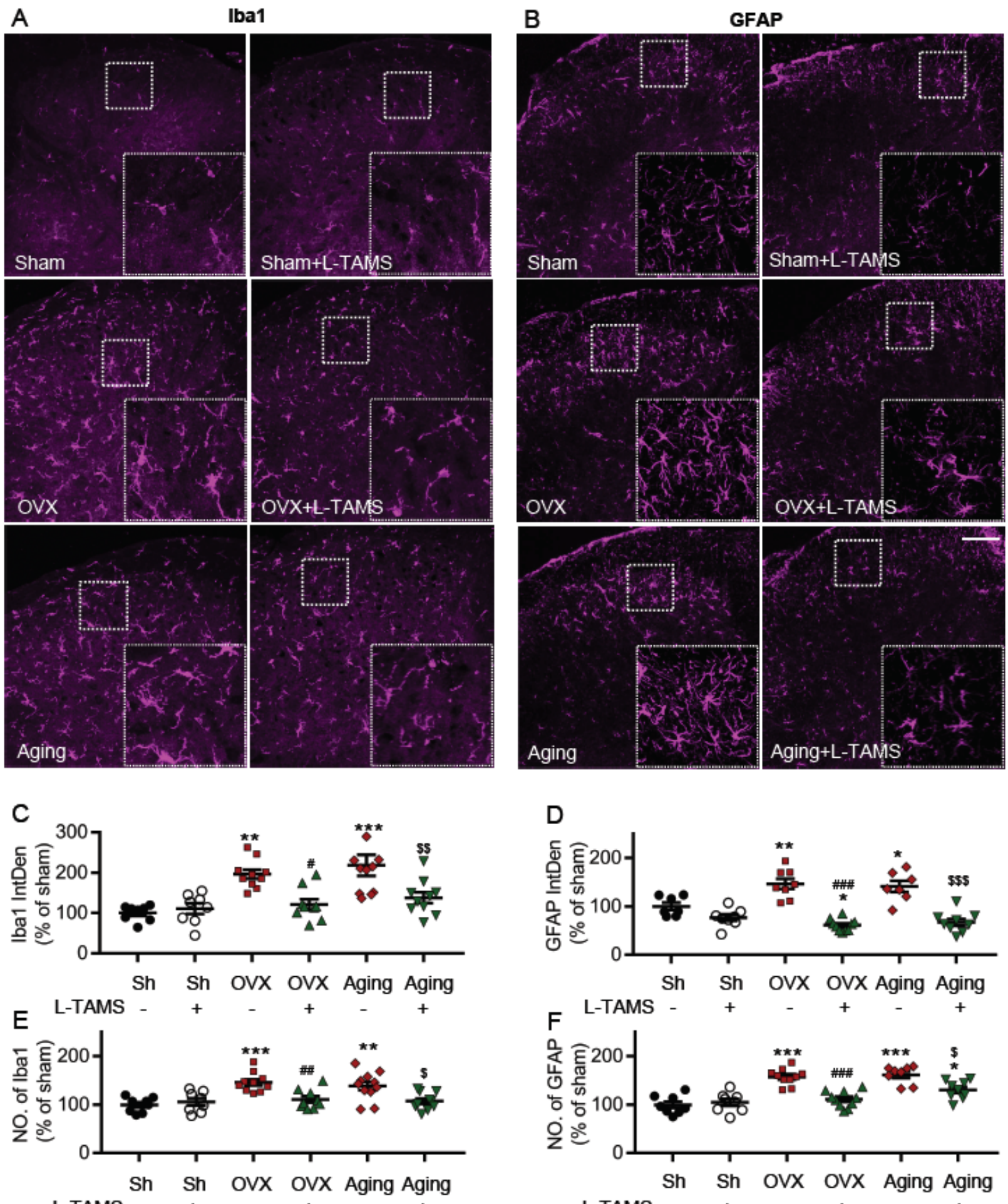

L-TAMS - $+\quad-\quad+\quad-\quad+$

\section{Figure 5}

Oral application of L-TAMS inhibits the activation of microglia and astrocytes in spinal dorsal horn induced by ovariectomy and aging. ( $A$ and $B$ ) Representative confocal images of the immunofluorescence staining of Iba1 (A) and GFAP (B) in spinal dorsal horn of different groups. Scale bar: $100 \mu \mathrm{m}$. (C and D) Statistical analysis of immunofluorescence intensity of Iba1 (C) and GFAP (D) in different groups ( $n=3-4$ mice/group, 2-3 sections/mouse). (E and F) The count of Iba1+ cell (E) and 
GFAP+ cell (F) in each 20هfield were statistically analyzed ( $n=3-4$ mice/group, 2-3 sections/mouse). The

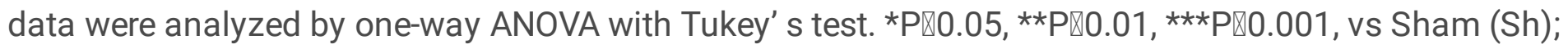

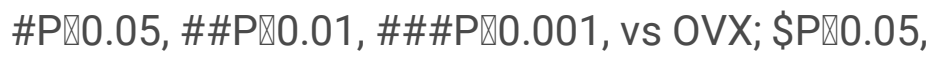

$$
P \square 0.01,
$$

\$P $₫ 0.001$, vs Aging.
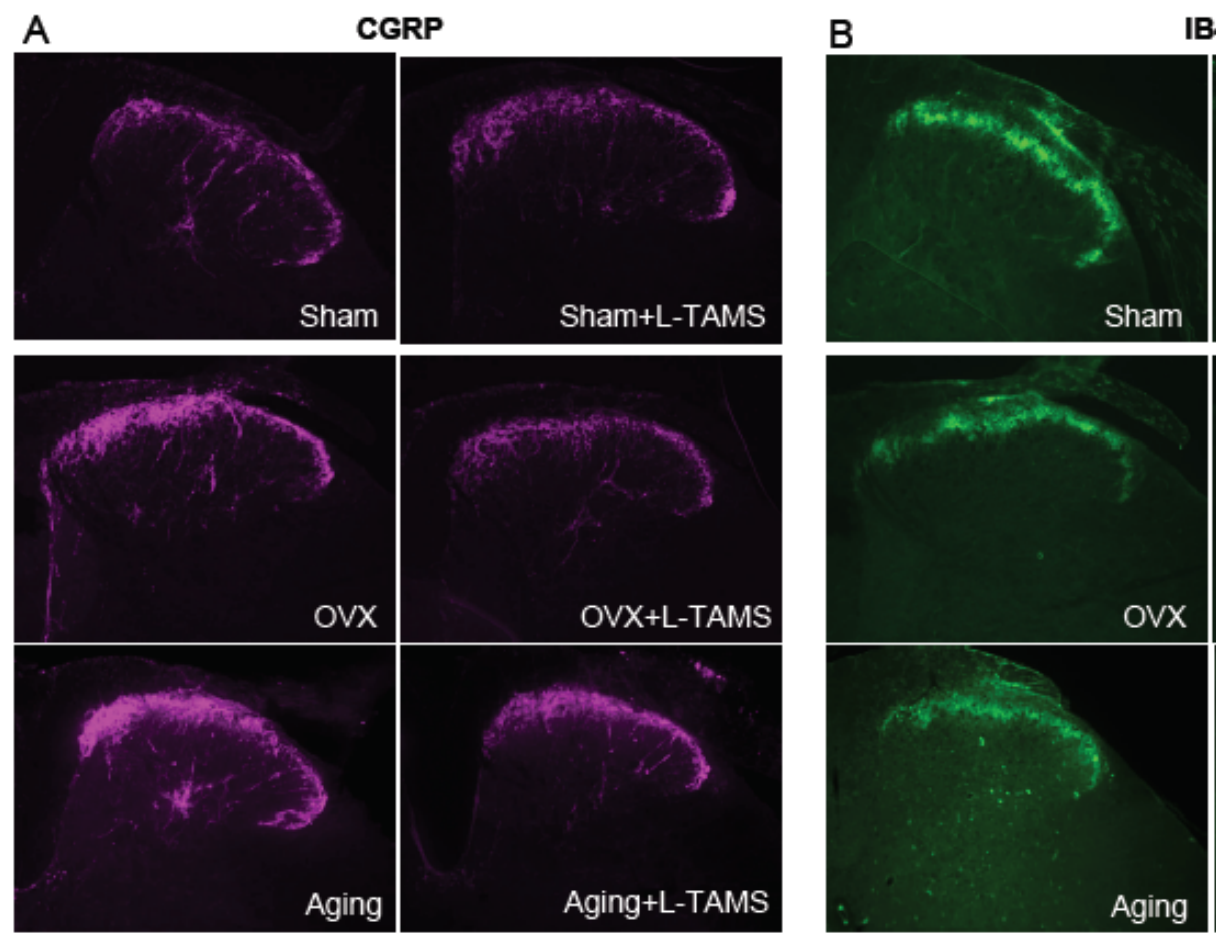

IB4

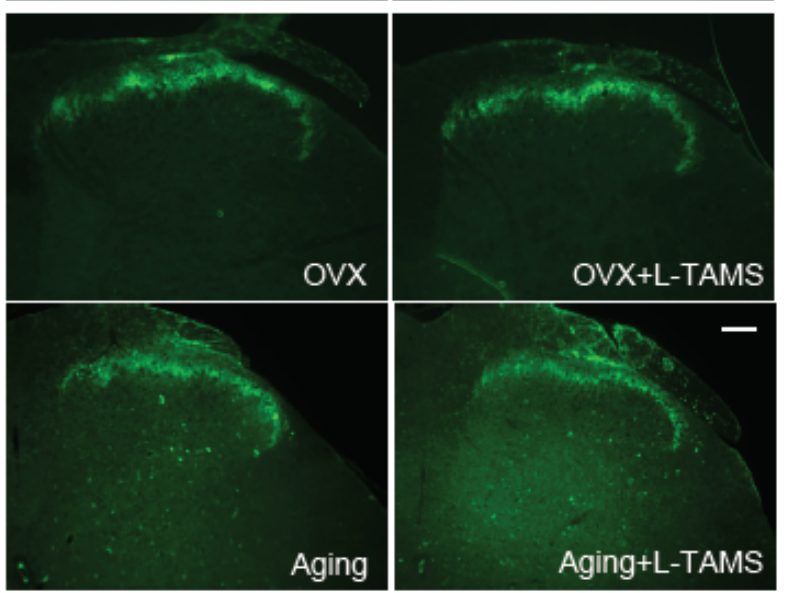

C

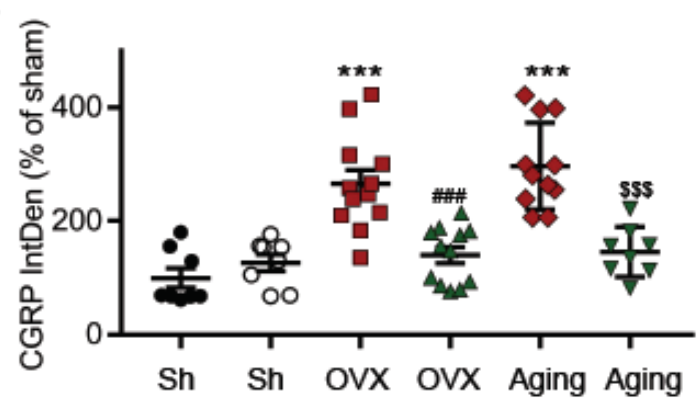

D

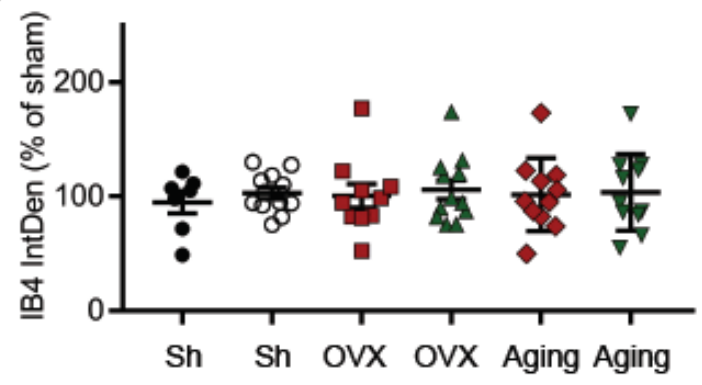

L-TAMS - $+\quad-\quad+\quad-$

L-TAMS
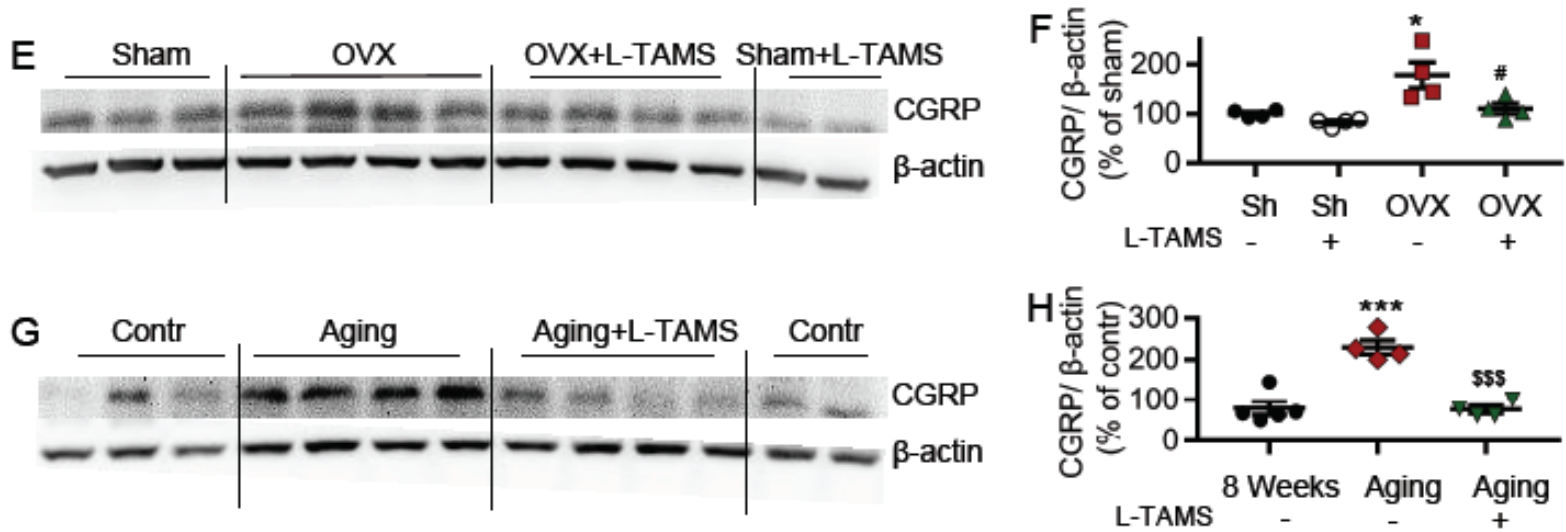

Figure 6 
Oral application of L-TAMS prevents the CGRP increase in ovariectomized mice and reverses the CGRP increase in aging mice in spinal dorsal horn. ( $A$ and $B$ ) Representative immunofluorescent staining images of CGRP (A) and IB4 (B) in spinal dorsal horn of different groups. Scale bar: $100 \mu \mathrm{m}$. (C and D) Oral application of L-TAMS significantly attenuates the CGRP sprouting in OVX and aging mice. There was no significant difference in the expression of IB4 among the groups ( $n=3-4$ mice/group, 2-3 sections/mouse). (E and F) Representative Western blots (E) and statistical analysis (F) show the CGRP levels in spinal dorsal horn in Sham, Sham + L-TAMS, OVX, and OVX+ L-TAMS groups ( $\mathrm{n}=4$ per group). $(G$ and $H)$ Representative Western blots $(G)$ and statistical analysis $(H)$ show the CGRP levels in spinal dorsal horn in control (8 weeks), Aging and Aging + L-TAMS groups ( $n=4-5$ per group). The data were

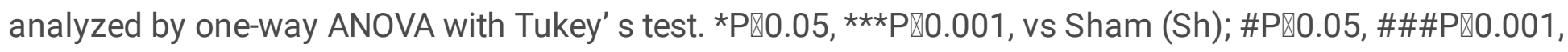
vs OVX; \$\$P区0.001, vs Aging. 

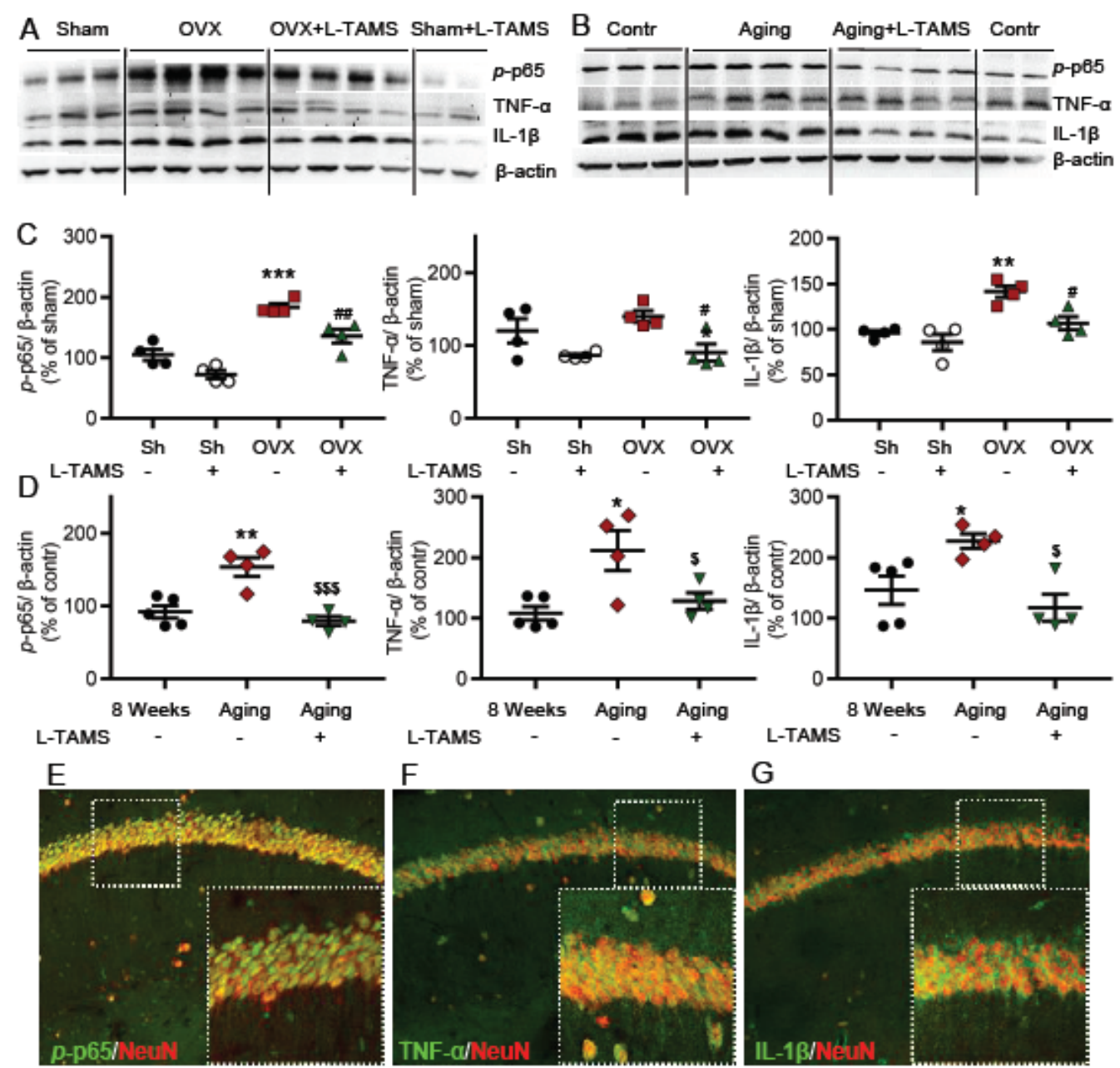

F

G
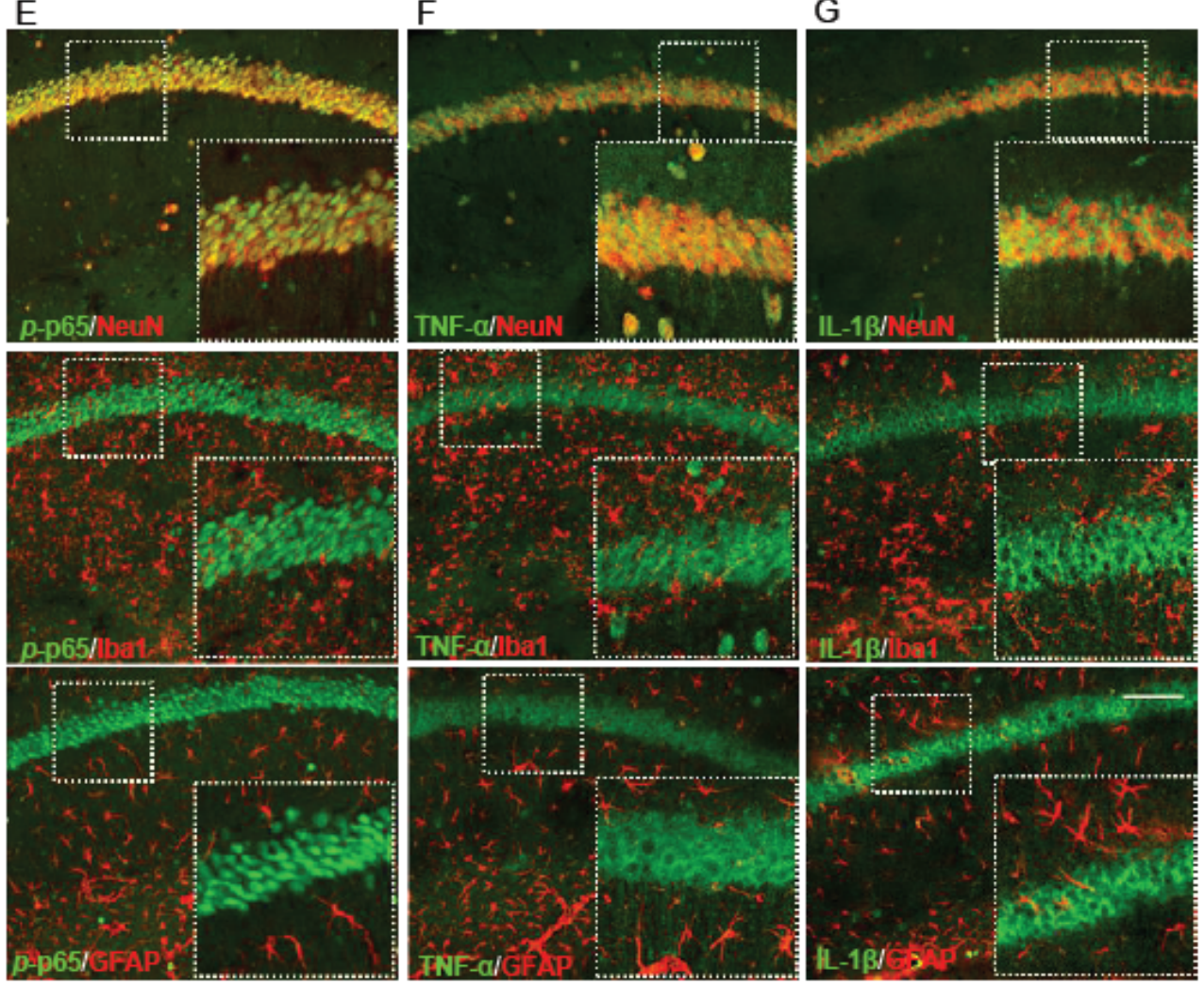

Figure 7

Oral application of L-TAMS attenuates the activation of NF-KB and upregulation of TNF-a and IL-1 in hippocampal CA1 region of ovariectomized and aging mice. (A and C) Representative Western blots (A) and statistical analysis (C) show the protein levels of p-p65, TNF-a, and IL-1 $\beta$ in hippocampi in indicated groups ( $n=4$ per group). (B and D) Representative Western blots (B) and statistical analysis (D) show the protein levels of p-p65, TNF-a, and IL-1 $\beta$ in hippocampi in control (8 weeks), Aging and Aging + L-TAMS 
groups ( $n=4-5$ per group). The data were analyzed by one-way ANOVA with Tukey's test. *P『0.05, **P区

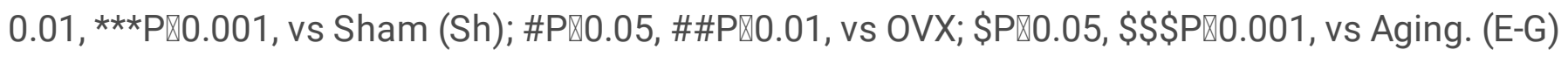

Representative confocal images of the double immunofluorescence staining shows that p-p65 $(E)$ is mainly located in the nuclei of hippocampal CA1 neurons. TNF- $\mathrm{a}(\mathrm{F})$, and IL-1 $\mathrm{I}(\mathrm{G})$ is mainly located in the cytoplasm of hippocampal CA1 neurons. Scale bar: $100 \mu \mathrm{m}$.
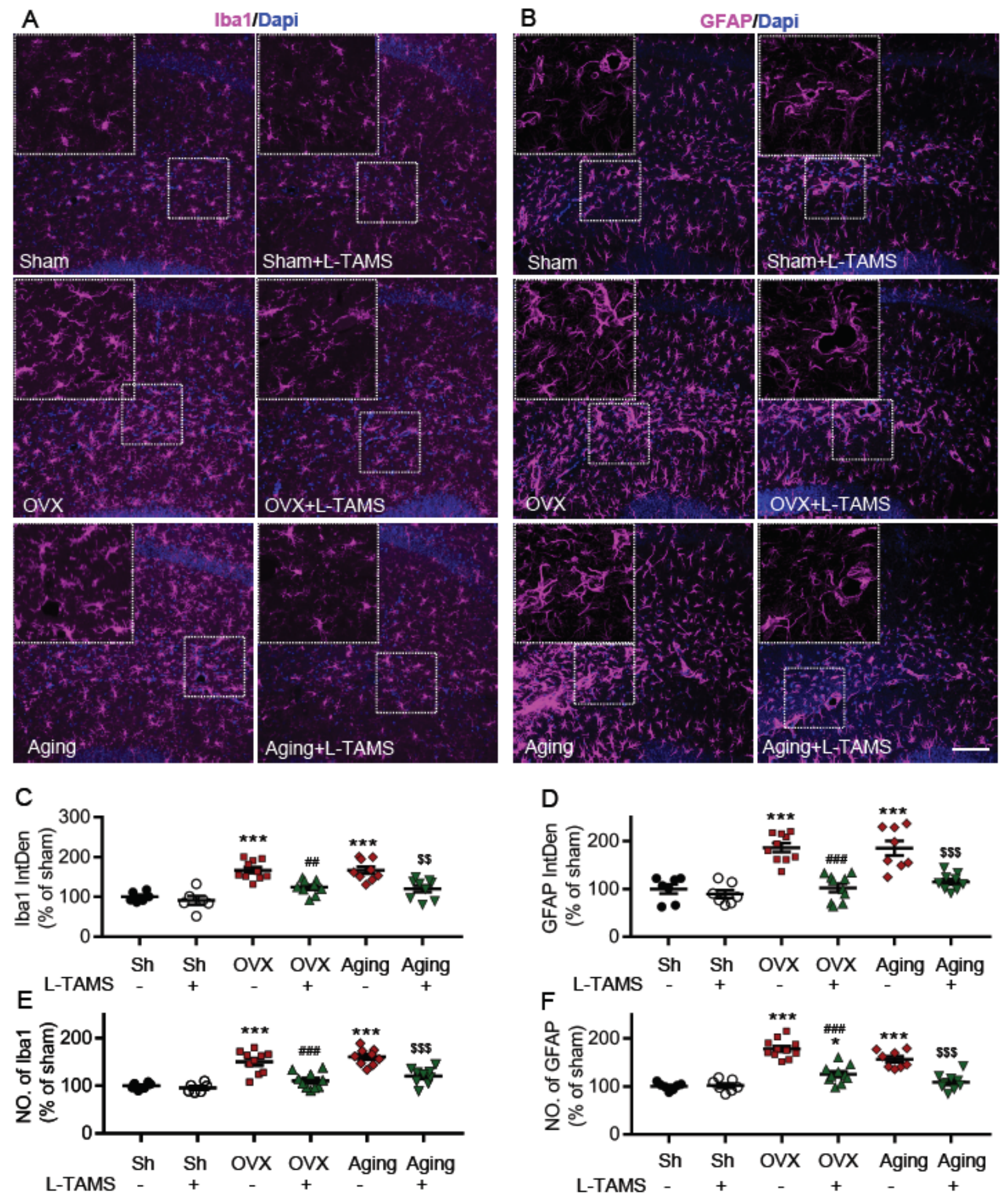

Figure 8 
Oral application of L-TAMS attenuates the activation of microglia and astrocytes in hippocampal induced by ovariectomy and aging. ( $A$ and $B$ ) Representative confocal images of the immunofluorescence staining of Iba1 (A囚and GFAP (B) in the different groups as indicated, Scale bar: $100 \mu \mathrm{m}$. (C and D) Statistical analysis of immunofluorescence intensity of Iba1 (C) and GFAP (D) in hippocampal of different groups ( $n=3-4$ mice/group, 2-3 sections/mouse). ( $E$ and $F$ ) The count of Iba1+ cell $(E)$ and GFAP+ cell $(F)$ in each 20区field were statistically analyzed ( $n=3-4$ mice/group, 2-3 sections/mouse). The

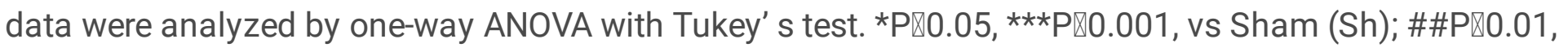
\#\#\#Pख0.001, vs OVX;

$$
P \square 0.01,
$$

$\$ P \llbracket 0.001$, vs Aging.
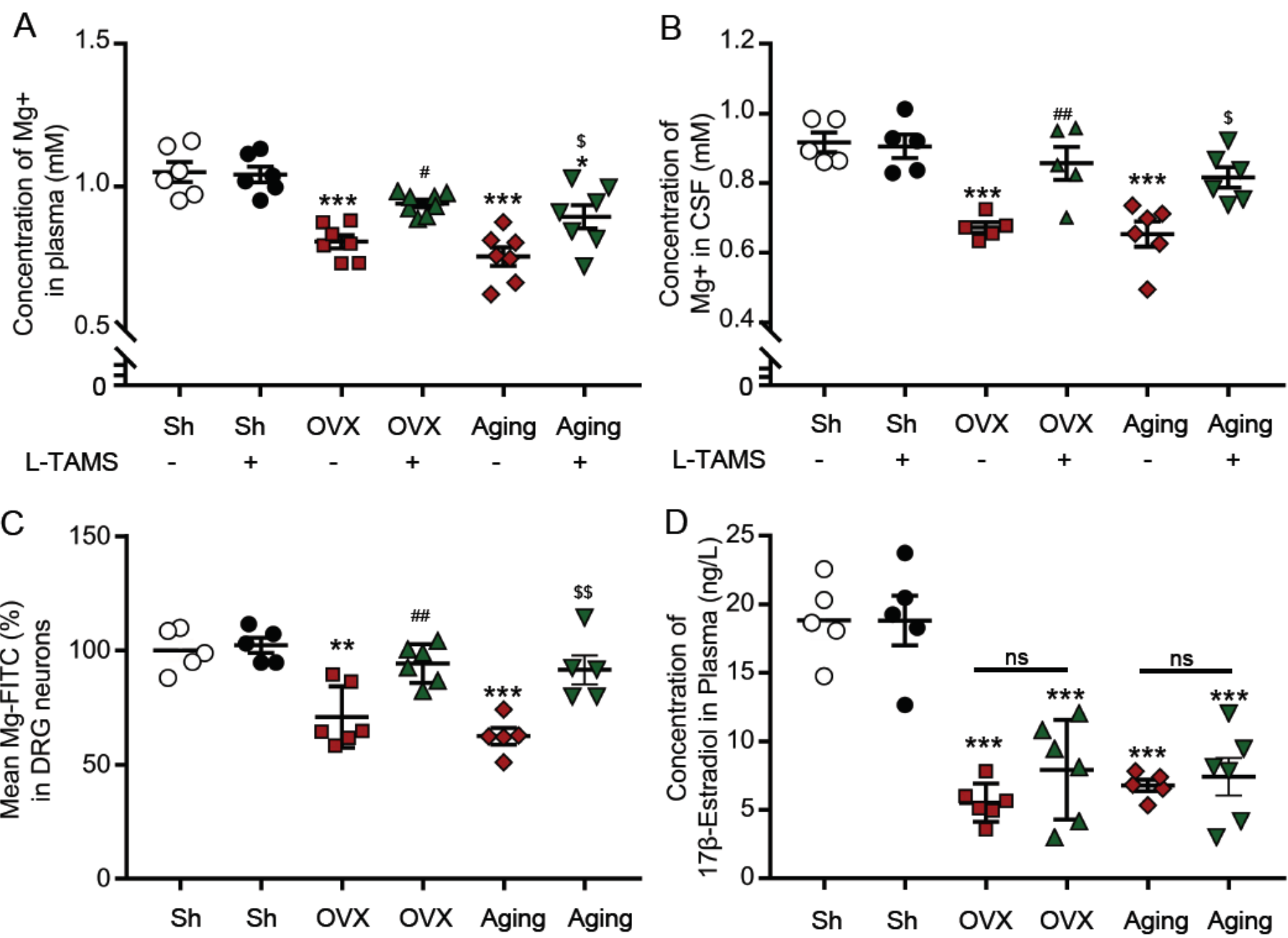

L-TAMS

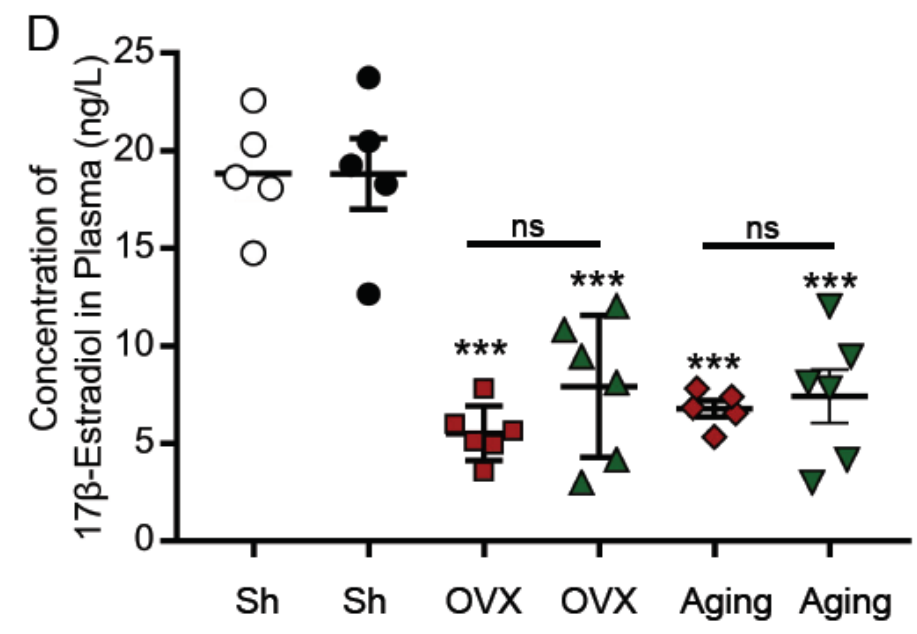

L-TAMS - $+\quad-\quad+\quad-\quad+$

Figure 9

Oral L-TAMS attenuates magnesium deficits but not estrogen decline in ovariectomized and aging female mice. (A-C) Free Mg2+ concentrations in the plasma ( $A, n=6-8$ per group), CSF (B, $n=5-6$ per group) and 
inside DRG neurons ( $C, n=5-6$ per group) in indicated groups are shown. (D) The plasma concentration of $17 \beta$-Estradiol in each group was measured by ELISA ( $n=5-6$ per group). The data were analyzed by

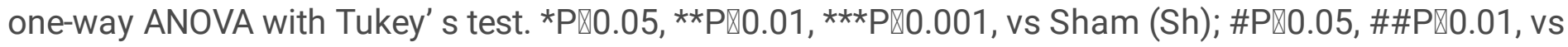
OVX; \$P $₫ 0.05, \$ \$ P \otimes 0.01$, vs Aging.
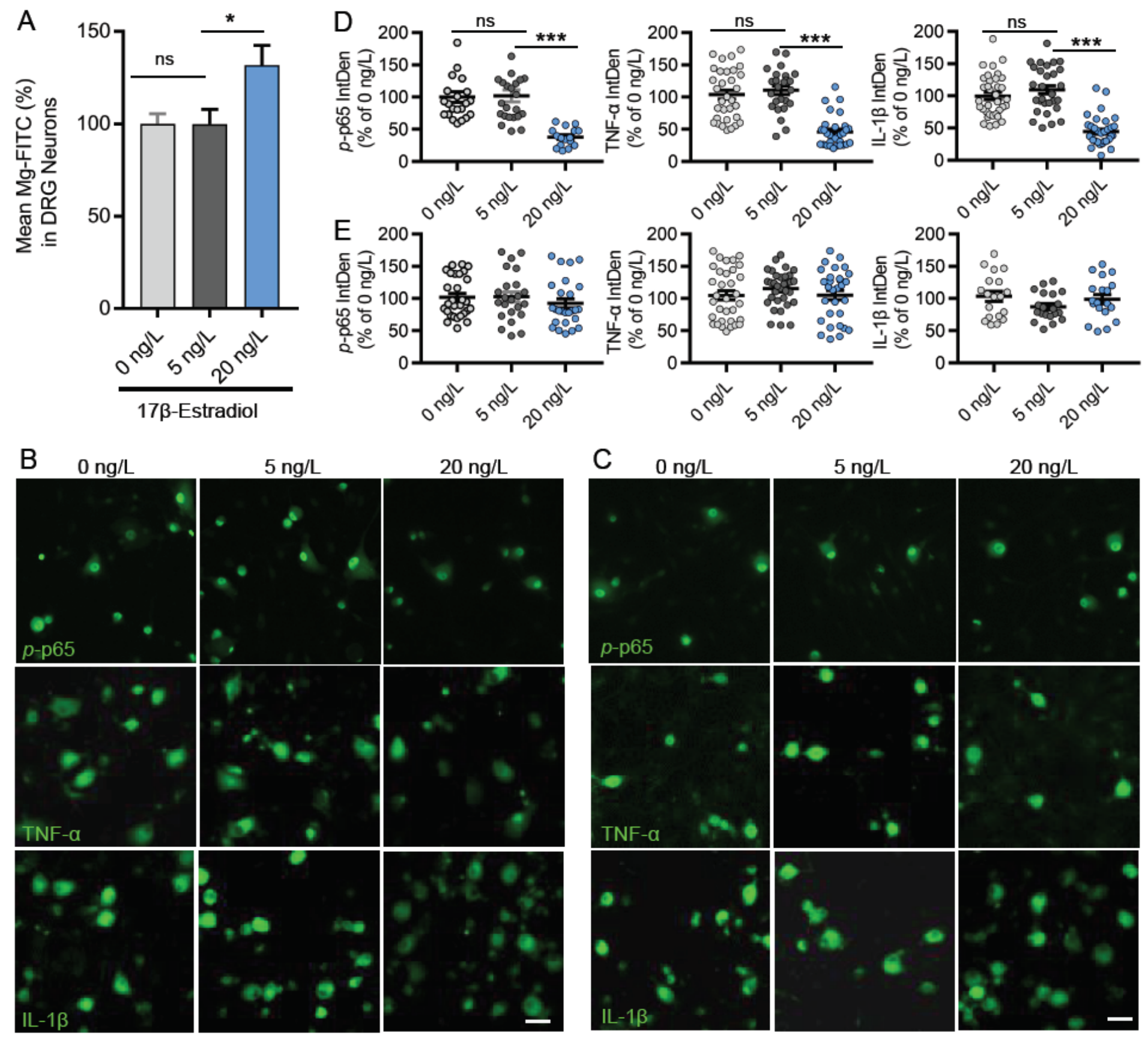

\section{Figure 10}

Estrogen elevates intracellular Mg2+ and prevents the activation of NF-KB in cultured DRG neurons. (A) Intracellular free $\mathrm{Mg} 2+$ in cultured DRG neurons was determined by multifunctional microplate reader ( $n=22-24$ plate/group). (B and C) Representative immunofluorescent staining images show the expressions of $p-p 65$, TNF- $a$ and IL-1 $\beta$ in DRG neurons cultured in normal medium containing $0.7 \mathrm{mM}$ $\mathrm{Mg} 2+(\mathrm{B})$ and in $\mathrm{Mg} 2+$ free medium $(\mathrm{C})$ in the presence of different concentrations of $17 \beta$-Estradiol; 
Scale bar: $20 \mu \mathrm{m}$. (D and E) Statistical analysis of immunofluorescence intensities of p-p65, TNF-a and IL-1 $\beta$ in DRG neurons cultured in normal medium (D) and Mg2+ free medium (E) with different concentrations of $17 \beta$-Estradiol ( $n=4-5$ fields per group; All the neurons in $20 \otimes$ fields were counted). The data were analyzed by one-way ANOVA with Tukey's test. *Pख0.05, ***P®0.001, vs $5 \mathrm{ng} / \mathrm{L} 17 \beta$-Estradiol.

\section{Supplementary Files}

This is a list of supplementary files associated with this preprint. Click to download.

- Supplementary1.pdf

- Supplementary2.pdf 